\title{
- Cobalt-Catalyzed Ammonia Borane Dehydrogenation: Mechanistic Insight and Isolation of a Cobalt Hydride-Amidoborane Complex
}

\author{
3 Joseph W. Nugent, Max García-Melchor,* and Alison R. Fout*
}

Cite This: https://dx.doi.org/10.1021/acs.organomet.0c00459

Read Online

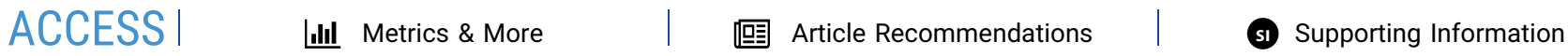

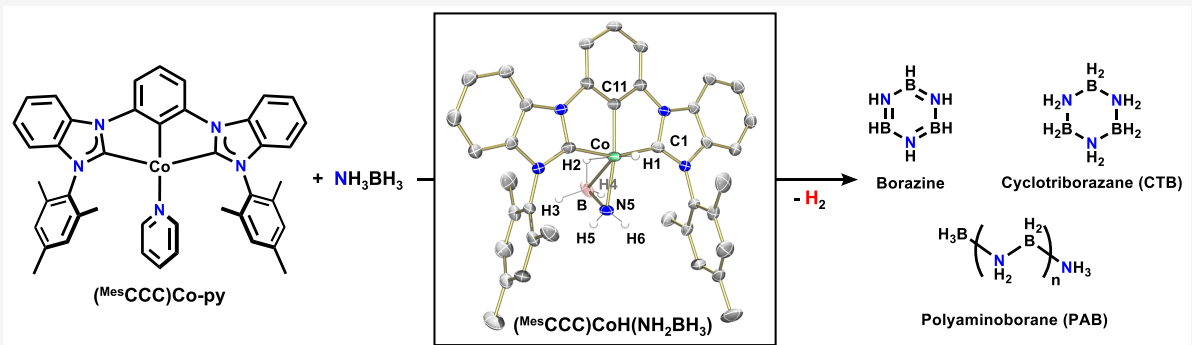

Cobalt-Catalyzed Ammonia Borane Dehydrogenation

Isolated Hydride-Amidoborane Complex

DFT Mechanistic Insight

4 ABSTRACT: A Co(I) complex featuring the electron-rich monoanionic bis(carbene) aryl pincer ligand $\left({ }^{\mathrm{Mes}} \mathrm{CCC}\right)\left({ }^{\mathrm{Mes}} \mathrm{CCC}=\right.$ 5 bis (2,4,6-trimethylphenyl-benzimidazol-2-ylidene)phenyl), ( $\left.{ }^{\mathrm{Mes}} \mathrm{CCC}\right) \mathrm{Co}$-py (1), was found to catalytically dehydrogenate ammonia 6 borane $\left(\mathrm{NH}_{3} \mathrm{BH}_{3}, \mathrm{AB}\right)$ in THF at $60{ }^{\circ} \mathrm{C}$. This process releases $1.7 \pm 0.1$ equiv of $\mathrm{H}_{2}$ per $\mathrm{AB}$ with simultaneous formation of both 7 soluble (borazine and polyborazylene) and insoluble (poly(aminoborane)) BN-containing species. To help elucidate the Co species 8 present under the catalytic conditions, 1 was reacted with a stoichiometric amount of AB in THF at room temperature, yielding 9 ( $\left.{ }^{\mathrm{Mes}} \mathrm{CCC}\right) \mathrm{CoH}\left(\mathrm{NH}_{2} \mathrm{BH}_{3}\right)(2)$, the first characterized hydride-amidoborane complex of a late transition metal. This complex was 10 characterized by multinuclear $\left({ }^{1} \mathrm{H},{ }^{11} \mathrm{~B}\right.$, and $\left.{ }^{13} \mathrm{C}\right) \mathrm{NMR}$ and IR spectroscopies as well as X-ray crystallography. Formation of 2 via $11 \mathrm{~N}-\mathrm{H}$ activation of $\mathrm{AB}$ across the $\mathrm{Co}(\mathrm{I})$ center of 1 was confirmed by the reaction of 1 with the deuterated isotopologues of $\mathrm{AB}$ and 12 was supported computationally by means of density functional theory (DFT) calculations. Isolated 2 was shown to catalyze AB 13 dehydrogenation, forming BN-containing products similar to $\mathbf{1}$, albeit at a slower rate. In both reactions starting with $\mathbf{1}$ or $\mathbf{2}$ as the 14 catalyst, $\mathbf{2}$ is observed throughout the catalytic dehydrogenation of AB. DFT calculations revealed plausible pathways for the 15 formation of aminoborane $\left(\mathrm{NH}_{2} \mathrm{BH}_{2}\right)$ from 2, the generation of soluble BN-containing products, as well as the on-metal 16 oligomerization of $\mathrm{AB}$ to produce the insoluble polymeric species. The complexes reported herein represent rare examples of 17 homogeneous cobalt catalysts for the dehydrogenation of $\mathrm{AB}$.

19 Amine boranes have been studied extensively for their ability 20 to act as hydrogen storage materials. ${ }^{1,2}$ Ammonia borane (AB) 21 has been of particular interest with the highest percentage of 22 hydrogen (19.1 wt \%) of all of the amine boranes. Researchers 23 have sought to develop both homogeneous and heterogeneous 24 systems to catalyze the release of $\mathrm{H}_{2}$ from amine boranes under 25 mild conditions. 3,4 These compounds feature both hydridic $26(\mathrm{~B}-\mathrm{H})$ and protic $(\mathrm{N}-\mathrm{H})$ hydrogens which facilitate hydro27 gen release from these compounds; however, the varied modes 28 of activation of these hydrogens yields mechanisms that vary 29 widely with different experimental conditions and catalyst 30 choice. $^{5}$

31 Much progress has been made with second- and third-row 32 transition metal catalysts toward understanding the complex 33 homogeneous mechanisms, ${ }^{6}$ but insight on how first-row 34 transition metals perform this dehydrogenation is still lacking.
First-row examples of $\mathrm{Ni}^{7,8} \mathrm{Ti}^{9-14} \mathrm{Mn},{ }^{15} \mathrm{Cr},{ }^{16,17}$ and, 35 increasingly, $\mathrm{Fe}^{18-25}$ complexes for homogeneous amine 36 borane dehydrogenation have been demonstrated; however, 37 for cobalt, there have only been a handful of published 38 examples as depicted in Figure 1. These include a (PBP)Co $39 \mathrm{fl}$ pincer complex reported by Peters and $\mathrm{Lin}^{26}{ }^{26} \mathrm{Cp}$-based ${ }_{40}$ cobalt complex by Waterman and co-workers, ${ }^{27}$ tripodal $\mathrm{EP}_{3} 41$ $(\mathrm{E}=\mathrm{N}$ and $\mathrm{P})$ cobalt complexes by Rossin, Shubina, and co- 42 workers, $^{28}$ a highly reduced diimine cobaltate complex by 43

Received: July 6, 2020 
<smiles>CCCCP1CN2c3ccccc3N(CC(C)C)P1CN2N</smiles><smiles>[R]OC1(C(=O)O)C=C1C(=O)O</smiles>

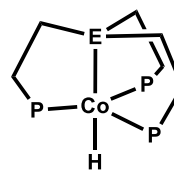

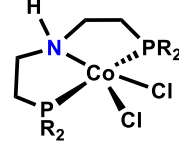
$P=P P h_{2}$
$E=N$ or $P$ $\mathbf{R}={ }^{\mathrm{i}} \mathrm{Pr}$ or $\mathbf{C y}$

Peters 2013

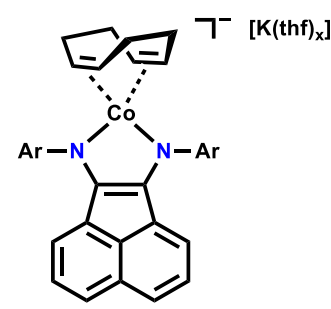

$\mathrm{Ar}=$ Dipp or Mes Wolf 2019

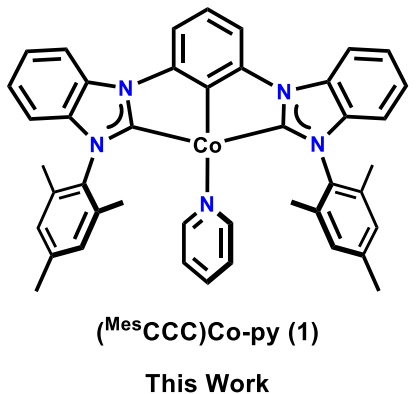

This Work

Figure 1. Examples of reported molecular cobalt catalysts for amine borane dehydrogenation. ${ }^{26-30}$

44 Wangelin, Wolf, and co-workers, ${ }^{29}$ and most recently a (PNP) 45 Co complex by Weller and co-workers. ${ }^{30}$

Previously we have shown the low-valent ( $\left.{ }^{\text {Dipp }} \mathrm{CCC}\right) \mathrm{Co}$ and 46 ( $\left.{ }^{\mathrm{Mes}} \mathrm{CCC}\right) \mathrm{Co}$ pincer complexes $\left({ }^{\mathrm{Dipp}} \mathrm{CCC}=\right.$ bis(2,6-diisopro- 47 pylphenyl-benzimidazol-2-ylidene)phenyl, ${ }^{\text {Mes }} \mathrm{CCC}=$ bis- 48 (mesityl-benzimidazol-2-ylidene)phenyl) to be competent for 49 catalytic hydrosilylation, ${ }^{31}$ hydroboration, ${ }^{32}$ and (semi)- 50 hydrogenation. ${ }^{33-35}$ The ability of these complexes to activate 51 $\mathrm{E}-\mathrm{H}$ bonds $(\mathrm{E}=\mathrm{Si}, \mathrm{B}$, or $\mathrm{H})$ in multiple hydrofunctionaliza- 52 tion reactions prompted us to apply these cobalt complexes 53 toward $A B$ dehydrogenation. Herein we report the catalytic 54 dehydrogenation of $\mathrm{AB}$ with ( ${ }^{\mathrm{Mes}} \mathrm{CCC}$ ) Co-py (1), resulting in 55 the isolation of the first example of a hydride-amidoborane 56 complex of a late transition metal. The insights gained from 57 this well-defined species are expected to inspire more efficient 58 cobalt pincer complexes for amine borane dehydrogenation. $\quad 59$

\section{RESULTS AND DISCUSSION}

60

Stoichiometric Reactivity of $\mathbf{1}$ with $\mathrm{AB}$ : Isolation and 61 Characterization of ( $\left.{ }^{\text {Mes }} \mathrm{CCC}\right) \mathrm{CoH}\left(\mathrm{NH}_{2} \mathrm{BH}_{3}\right)$ (2). Initial 62 experiments sought to determine the reactivity of the reduced 63 $\mathrm{Co}(\mathrm{I})$ species, 1 , with $\mathrm{AB}$ in a stoichiometric fashion. The 64 addition of $\mathrm{AB}$ ( 1.1 equiv) to $\mathbf{1}$ (Figure $2 \mathrm{a}$ ) in THF at room $65 \mathrm{f} 2$ temperature resulted in a color change from red to brown over 66 the course of minutes and, upon workup, cleanly yielded a 67 brown powder in excellent yield (93\%). Crystallographic 68 characterization of this complex revealed ( $\left.{ }^{\mathrm{Mes}} \mathrm{CCC}\right) \mathrm{CoH}-69$ $\left(\mathrm{NH}_{2} \mathrm{BH}_{3}\right)$ (2), seen in Figure 2b. This complex is best 70 described as a hydride-amidoborane $\mathrm{Co}$ (III) species where the 71<smiles></smiles>
(MesCCC)Co-py (1)

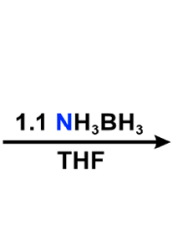<smiles>Cc1ccccc1NC(C)(C)C</smiles>

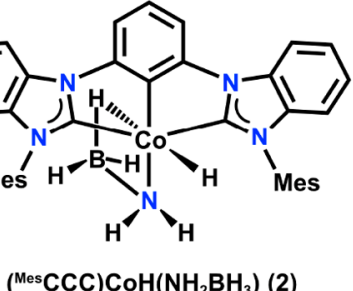

( $\left.{ }^{\mathrm{Mes}} \mathrm{CCC}\right) \mathrm{CoH}\left(\mathrm{NH}_{2} \mathrm{BH}_{3}\right)(2)$ b)

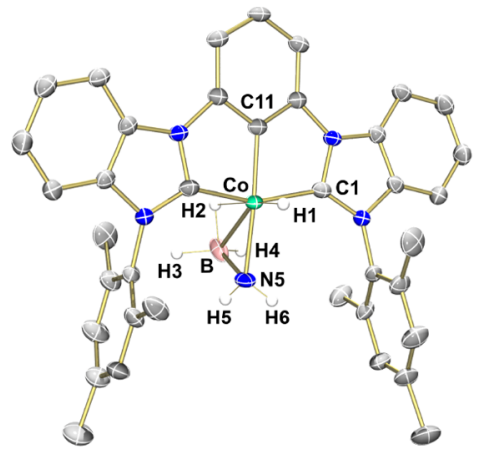

c)

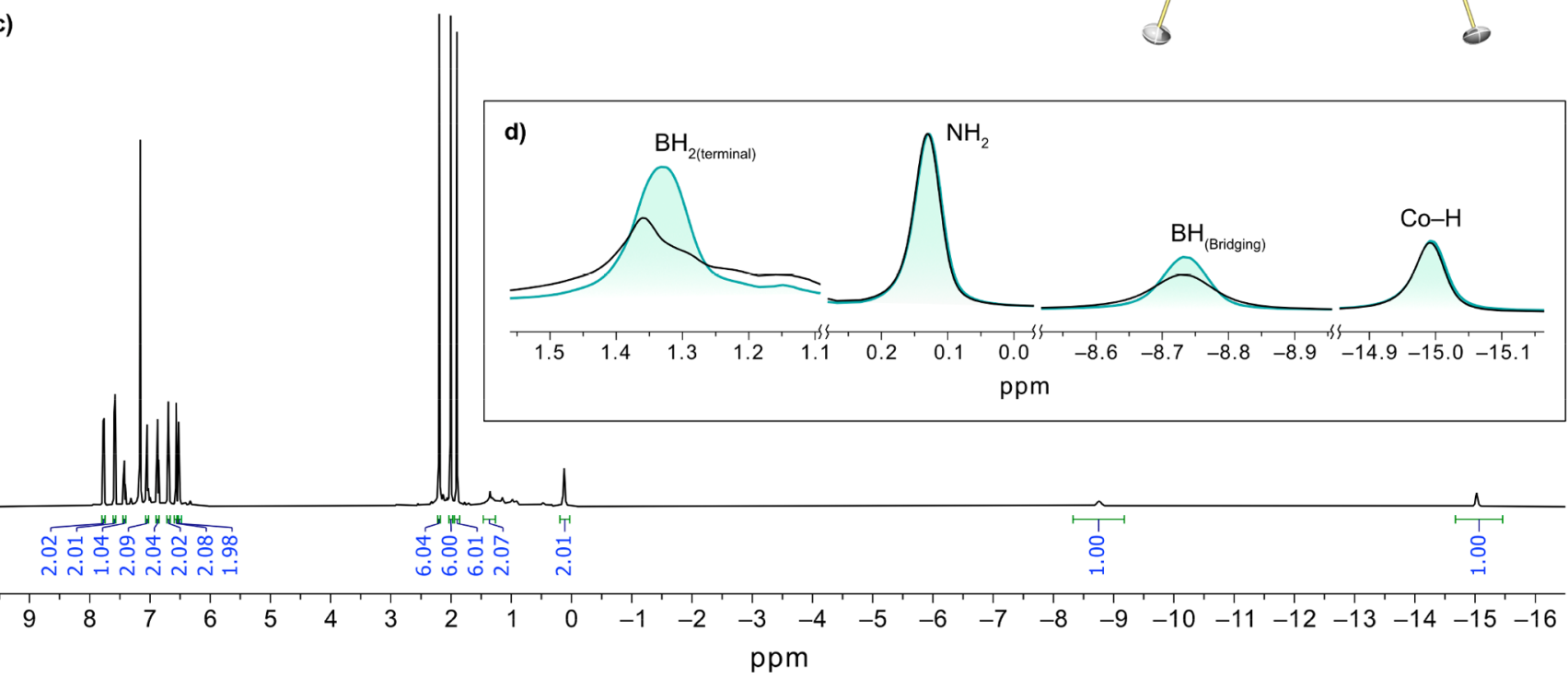

Figure 2. (a) Synthesis of complex 2. (b) Crystal structure of 2 (ellipsoids at 50\% probability, half of molecule symmetry generated). Hydrogen atoms on the ligand are omitted for clarity. Selected bond lengths $[\AA \AA]$ : Co-H1, 1.53(4); Co-N5, 2.000(3); Co-B, 2.252(8); Co-H2, 1.85(4); $\mathrm{B}-\mathrm{N} 5,1.547(6)$; $\mathrm{Co}-\mathrm{C} 1,1.918(11)$; Co-C11, 1.865(3). (c) ${ }^{1} \mathrm{H}$ NMR spectrum of 2 in $\mathrm{C}_{6} \mathrm{D}_{6}$. (d) Overlaid ${ }^{1} \mathrm{H}$ NMR (black trace) and ${ }^{1} \mathrm{H}\left\{{ }^{11} \mathrm{~B}\right\}$ NMR (teal trace) spectra of upfield resonances of 2. 
$72 \mathrm{~N}-\mathrm{H}$ bond of $\mathrm{AB}$ has been oxidatively added across the $\mathrm{Co}(\mathrm{I})$ 73 center of 1 to yield 2 . The amidoborane $\left(\mathrm{NH}_{2} \mathrm{BH}_{3}{ }^{-}\right)$fragment 74 of 2 is bound to the Co center through a $\mathrm{Co}-\mathrm{N}$ bond and a $75 \mathrm{Co}-\mathrm{H}-\mathrm{B}$ bridging interaction with the hydride positioned 76 trans to the bridging $\mathrm{B}-\mathrm{H}$ moiety $(\mathrm{H} 1-\mathrm{Co}-\mathrm{H} 2=$ $\left.77173.8(2.6)^{\circ}\right)$.

78 The activation of the $\mathrm{N}-\mathrm{H}$ bond over the $\mathrm{B}-\mathrm{H}$ bond at the 79 metal center is somewhat unsurprising given the BDE's of 95.5 80 and $102.0 \mathrm{kcal} \mathrm{mol}^{-1}$, respectively. ${ }^{36-39}$ A cobalt amidoborane 81 complex was suggested computationally by Shubina and co82 workers upon $\mathrm{N}-\mathrm{H}$ activation at a $\mathrm{Co}-\mathrm{H}$ species followed by 83 release of $\mathrm{H}_{2}{ }^{28}$ however, the process presented herein does 84 not occur in the presence of a hydride species. To our 85 knowledge, only three other structurally characterized 86 complexes containing the $\mathrm{NH}_{2} \mathrm{BH}_{3}{ }^{-}$anion bound to a 87 transition metal have been reported including the $(\mathrm{Cp})_{2} \mathrm{ZrCl}$ $88\left(\mathrm{NH}_{2} \mathrm{BH}_{3}\right)$ and $(\mathrm{Cp})_{2} \mathrm{ZrH}\left(\mathrm{NH}_{2} \mathrm{BH}_{3}\right)$ complexes synthesized 89 from $(\mathrm{Cp})_{2} \mathrm{ZrCl}_{2}$ with 1 and 2 equiv of $\mathrm{AB}$ and $n \mathrm{BuLi}$ 90 respectively, ${ }^{40}$ and $(\mathrm{Cp})_{2} \mathrm{Ti}\left(\mathrm{NH}_{2} \mathrm{BH}_{3}\right)$ synthesized by reacting $91(\mathrm{Cp})_{2} \mathrm{TiCl}_{2}$ with $\mathrm{K}\left(\mathrm{NH}_{2} \mathrm{BH}_{3}\right){ }^{41}$ Although the geometry and 92 ligand fields are different in these cases, the structural 93 parameters of $\mathbf{2}$ compare favorably to these examples when 94 the contracted ionic radius of $\mathrm{Co}$ (III) is considered (see Figure $95 \mathrm{~S} 10) .{ }^{42}$ The formation of 2 represents a rare example of $\mathrm{N}-\mathrm{H}$ 96 activation to isolate an amidoborane species.

97 Recent examples by Manners and co-workers have found 98 that $\mathrm{Cp}$-based $\mathrm{Ti}$-amidoborane complexes are active in amine 99 borane dehydrocoupling. Specifically, Manners and co-workers 100 reported the $\mathrm{Cp}_{2} \mathrm{Ti}\left(\mathrm{Me}_{2} \mathrm{NBH}_{3}\right)$ complex as an active catalyst 101 for the dehydrocoupling of dimethylamine borane 102 (DMAB), ${ }^{10,14}$ and more recently, they have reported an 103 analogous amidoborane complex, $\mathrm{Cp}_{2}{ }_{2} \mathrm{Ti}\left(\mathrm{MeNHBH}_{3}\right)$, which 104 was crystallographically characterized following the reaction of $105 \mathrm{Cp}_{2}^{*} \mathrm{Ti}\left(\mathrm{CH}_{3}\right)$ with $\mathrm{MeNH}_{2} \mathrm{BH}_{3}$. ${ }^{13}$ The latter isolated 106 amidoborane was also found to be catalytically active when 107 reintroduced to the reaction. Webster and co-workers have 108 also suggested the participation of iron-amidoborane inter109 mediates during the dehydrocoupling of DMAB with a 110 (Nacnac)Fe complex and were able to isolate and crystallo111 graphically characterize the amidoborane intermediate with 112 two monomer units. ${ }^{25}$

113 Amidoborane complexes have also been studied and 114 implicated in alkaline earth (AE) metal complexes for amine 115 borane dehydrocoupling. Earlier work by Harder and co116 workers reported the crystal structures of $\mathrm{AE}$ metals with the $117 \mathrm{NH}_{2} \mathrm{BH}_{3}^{-}$anion including ( ${ }^{-}$ipp $\left.\mathrm{Nacnac}\right) \mathrm{Ca}\left(\mathrm{NH}_{2} \mathrm{BH}_{3}\right)$ 118 (THF $)_{2},{ }^{43}$ and the $\mathrm{Mg}$ analogue ( $\left.{ }^{\mathrm{Dipp}} \mathrm{Nacnac}\right) \mathrm{Mg}\left(\mathrm{NH}_{2} \mathrm{BH}_{3}\right)$ 119 (THF). ${ }^{44}$ More recent work by Hill and co-workers has 120 extended the study of the AE-amidoborane species and applied 121 them in amine borane dehydrocoupling reactions ${ }^{45-47}$

122 Characterization of 2 by ${ }^{1} \mathrm{H}$ NMR spectroscopy revealed a 123 diamagnetic complex with three $6 \mathrm{H}$ resonances corresponding 124 to the mesityl methyl groups, consistent with a $C_{s}$-symmetric 125 complex (Figure 2c). The spectrum also contained upfield 126 resonances at $0.12(2 \mathrm{H}),-8.76(1 \mathrm{H})$, and $-15.03(1 \mathrm{H}) \mathrm{ppm}$. 127 The assignment of these resonances was aided by collecting 128 the ${ }^{1} \mathrm{H}\left\{{ }^{11} \mathrm{~B}\right\}$ NMR spectrum of 2 (Figure $2 \mathrm{~d}$ ). Upon 129 decoupling of the ${ }^{11} \mathrm{~B}$ nucleus, the resonance at $-8.76 \mathrm{ppm}$ 130 and a previously obscured broad resonance at $1.33 \mathrm{ppm}$ 131 changed peak shape to form sharper resonances. Due to the 132 peak shape change upon decoupling of the ${ }^{11} \mathrm{~B}$ nucleus and 133 literature precedence for amidoborane moieties, the reso134 nances at 1.33 and $-8.76 \mathrm{ppm}$ were assigned to $\mathrm{BH}_{2 \text { (Terminal) }}$ and $\mathrm{BH}_{(\text {Bridging })}$ protons, respectively, while the resonances at 135 0.14 and $-14.97 \mathrm{ppm}$ were assigned to the protons of $\mathrm{NH}_{2} 136$ and $\mathrm{Co}-\mathrm{H}$, respectively. ${ }^{40,41}$ Complex 2 also featured a 137 corresponding ${ }^{11} \mathrm{~B}$ NMR resonance at $-28.1 \mathrm{ppm}$ assigned to 138 the boron atom of the $\mathrm{NH}_{2} \mathrm{BH}_{3}{ }^{-}$fragment (Figure S3). 139 Variable-temperature NMR experiments of 2 in toluene- $d_{8} 140$ revealed no fluxional character of this complex up to $80{ }^{\circ} \mathrm{C} . \quad 141$

To further support the proposed $\mathrm{N}-\mathrm{H}$ oxidative addition 142 pathway to form 2, we turned to the deuterated isotopologues 143 of $\mathrm{AB}$. To this end, $\mathrm{NH}_{3} \mathrm{BD}_{3}$ and $\mathrm{ND}_{3} \mathrm{BH}_{3}$ were synthesized 144 and reacted with 1 at room temperature in THF to form 145 $\left({ }^{\mathrm{Mes}} \mathrm{CCC}\right) \mathrm{CoH}\left(\mathrm{NH}_{2} \mathrm{BD}_{3}\right)$ (2-BD) and ( $\left.{ }^{\mathrm{Mes}} \mathrm{CCC}\right) \mathrm{CoD}-146$ $\left(\mathrm{ND}_{2} \mathrm{BH}_{3}\right)$ (2-ND), respectively (Scheme 1). ${ }^{29}$ Consistent $147 \mathrm{~s} 1$

Scheme 1. Reaction of 1 with Deuterated Isotopologues of $\mathrm{AB}$

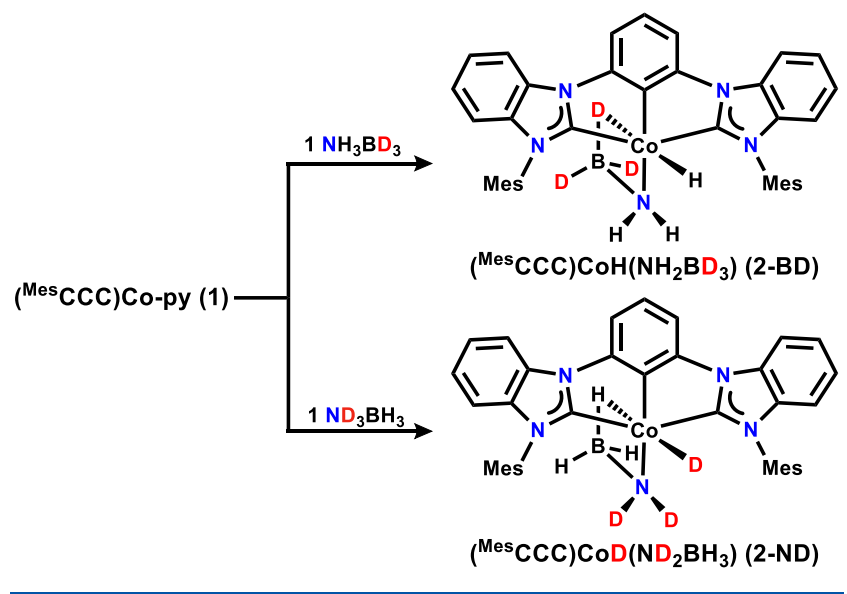

with the $\mathrm{N}-\mathrm{H}$ oxidative addition pathway, the resulting ${ }^{1} \mathrm{H} 148$ NMR spectrum of the reaction of 2-BD lacked the resonances 149 previously assigned to the $\mathrm{BH}_{2 \text { (Terminal) }}$ and $\mathrm{BH}_{(\text {Bridging) }}$ protons 150 and maintained the resonances assigned to the $\mathrm{Co}-\mathrm{H}$ and 151 $\mathrm{NH}_{2}$ protons (Figure S5). The ${ }^{2} \mathrm{H}$ NMR spectrum of 2-BD 152 showed the inverse picture with the corresponding $\mathrm{BD}_{2 \text { (Terminal) }} 153$ and $\mathrm{BD}_{(\text {Bridging })}$ resonances present. In a similar fashion, 2-ND 154 showed the enrichment of the $\mathrm{ND}_{2}$ and $\mathrm{Co}-\mathrm{D}$ resonances in 155 the ${ }^{2} \mathrm{H}$ NMR spectrum (Figure S6). The ${ }^{1} \mathrm{H}$ NMR spectrum of 156

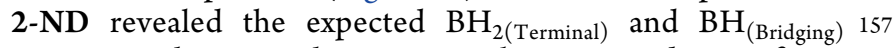
resonances; however, the spectrum also contained a significant 158 amount of $\mathrm{Co}-\mathrm{H}$ (1.00:2.18 integration ratio of $\mathrm{Co}-\mathrm{H} / 159$ $\left.\mathrm{BH}_{(\text {Bridging })}\right)$. Some of the $\mathrm{Co}-\mathrm{H}$ in this case is not only the 160 likely result of incomplete enrichment of the $\mathrm{ND}_{3} \mathrm{BH}_{3}$ (ca. 90\% 161 enriched by ${ }^{1} \mathrm{H}$ NMR integration) but also suggests that some 162 exchange with the hydride is possible. The difference in 163 integration between the $\mathrm{NH}_{2}(0.2)$ and $\mathrm{Co}-\mathrm{H}$ (1.0) 164 resonances is also notable because in theory the ratio should 165 be $2: 1$ if the difference came from the starting material. The 166 $\mathrm{Co}-\mathrm{H} / \mathrm{D}$ mixture of the product also results in the splitting of 167 the $\mathrm{BH}_{(\text {Bridging })}$ resonance in the ${ }^{1} \mathrm{H}$ NMR spectrum. A report 168 studying the IR and Raman spectra of $\mathrm{d}^{6}$ trans-dihydride 169 complexes found the substitution of a hydride for deuteride 170 resulted in changes in the charge gradient and density in these 171 species. $^{48}$ An effect of this sort may explain the differing 172 influence of a hydride or deuteride trans to the $\mathrm{BH}_{(\text {Bridging })}$ on 173 the chemical shift of this proton; however, more analogous 174 examples would be needed to support this hypothesis. Both 175 isotopic enrichment experiments are consistent with $\mathrm{N}-\mathrm{H} / \mathrm{D} 176$ 


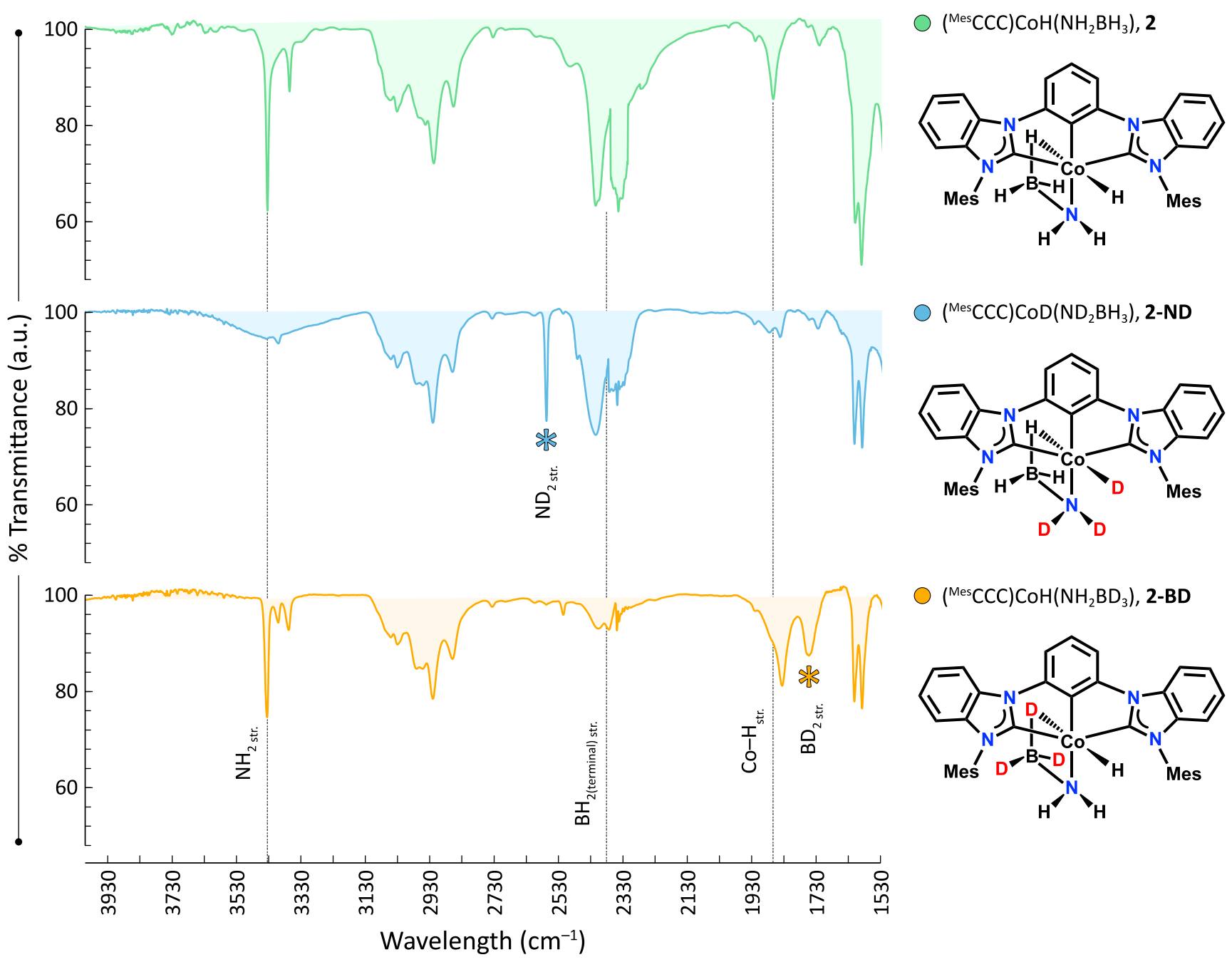

Figure 3. IR spectra $(\mathrm{KBr})$ of 2 (green), ( $\left.{ }^{\mathrm{Mes}} \mathrm{CCC}\right) \mathrm{CoD}\left(\mathrm{ND}_{2} \mathrm{BH}_{3}\right)$ (blue), and $\left({ }^{\mathrm{Mes}} \mathrm{CCC}\right) \mathrm{CoH}\left(\mathrm{NH}_{2} \mathrm{BD}_{3}\right)$ (orange). Asterisks mark new stretching frequencies corresponding to the deuterated species.

Scheme 2. Independent Synthesis of 2 from 3

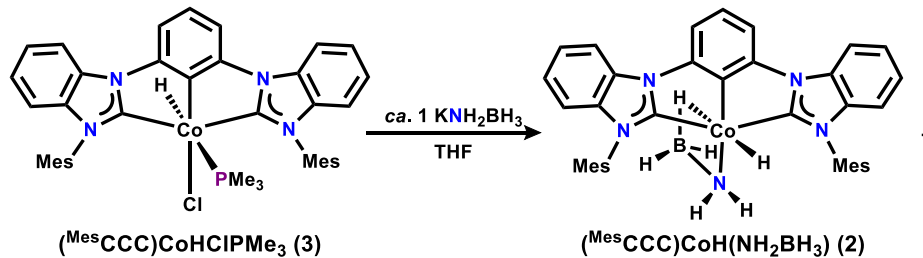

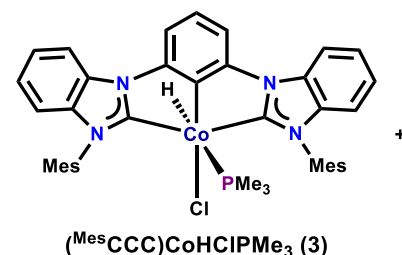

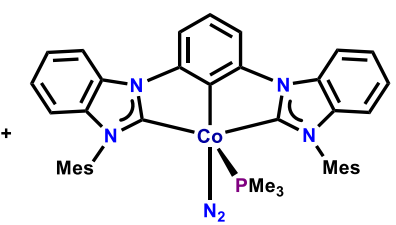

$\left({ }^{\mathrm{Mes}} \mathrm{CCC}\right) \mathrm{CoN}_{2} \mathrm{PMe}_{3}(4)$

177 activation of the $\mathrm{AB}$ substrates and further support the peak 178 assignments in the ${ }^{1} \mathrm{H}$ NMR spectrum.

179 Analysis of 2 by IR spectroscopy (Figure 3, green trace) 180 revealed stretching frequencies at $3434 \mathrm{~cm}^{-1}\left(\mathrm{NH}_{2}\right), 2415$ and $1812344 \mathrm{~cm}^{-1}\left(\mathrm{BH}_{2 \text { (Terminal })}\right)$, and $1862 \mathrm{~cm}^{-1}(\mathrm{Co}-\mathrm{H})$ which were 182 consistent with those reported for other amidoborane $e^{40,41}$ and $183 \mathrm{Co}-\mathrm{H}$ species. ${ }^{33}$ As with the NMR spectra of the deuterated 184 isotopologues of $\mathbf{2}$, the IR spectra were consistent with these 185 assignments as evidenced by the shift of the deuterated 186 positions' stretching frequencies in the corresponding IR 187 spectra. The IR spectrum of 2 -ND (Figure 3, blue trace) 188 revealed a shift of the $\mathrm{NH}_{2}$ stretching frequency at ca. 3400$1892567 \mathrm{~cm}^{-1}$ consistent with the reduced mass calculation for $190 \mathrm{ND}_{2}$ (calcd $\left.2513 \mathrm{~cm}^{-1}\right)$. This spectrum also lacked a significant peak at ca. $1860 \mathrm{~cm}^{-1}$ which is consistent with an 191 isotopically shifted Co-D frequency. The resulting Co-D 192 stretch could not be unambiguously assigned as it was lost in 193 the fingerprint region. The IR spectrum for 2-BD (Figure 3, 194 orange trace) featured a small peak at ca. 2375195 $\mathrm{cm}^{-1}\left(\mathrm{BH}_{2 \text { (Terminal) }}\right)$ resulting from incomplete deuteration of 196 the $\mathrm{B}-\mathrm{H}$ bonds and a peak at $1752 \mathrm{~cm}^{-1}$, which was consistent 197 with the shifted $\mathrm{BD}_{2 \text { (Terminal) }}$ stretching frequency (calcd 1753198 $\left.\mathrm{cm}^{-1}\right)$. The spectrum maintained the $\mathrm{Co}-\mathrm{H}$ peak at ca. 1860199 $\mathrm{cm}^{-1}$ and $\mathrm{NH}_{2}$ stretching frequency at ca. $3400 \mathrm{~cm}^{-1}$. Both 200 isotopically labeled samples help support the assignment of the 201 stretching frequencies in the IR spectra and are consistent with 202 the corresponding ${ }^{1} \mathrm{H}$ NMR resonances. 
204 Independent Synthesis of 2. Previously, we reported the 205 isolation of ( $\left.{ }^{\mathrm{Mes}} \mathrm{CCC}\right) \mathrm{CoHClPMe}_{3}$ (3) by the addition of $\mathrm{HCl}$. $206 \mathrm{Et}_{2} \mathrm{O}$ to ( $\left.{ }^{\mathrm{Mes}} \mathrm{CCC}\right) \mathrm{CoN}_{2} \mathrm{PMe}_{3}$ (4). ${ }^{33}$ We reasoned that 207 performing a salt metathesis reaction on 3 with $\mathrm{KNH}_{2} \mathrm{BH}_{3}$ 208 with simultaneous loss of phosphine would allow us to 209 independently synthesize 2. Addition of ca. 1 equiv of $210 \mathrm{KNH}_{2} \mathrm{BH}_{3}$ to 3 did result in the observation of a small 211 amount of 2 by ${ }^{1} \mathrm{H}$ NMR spectroscopy (Scheme 2); however, 212 a significant amount of 4 and unreacted 3 was also observed 213 (Figure S18). On the basis of the ${ }^{1} \mathrm{H}$ NMR spectrum, the 214 resulting ratio of complexes $2 / 3 / 4$ was approximately $1: 2.5: 5$. 215 This not only demonstrated that $\mathrm{KNH}_{2} \mathrm{BH}_{3}$ could in fact 216 perform a salt metathesis reaction with 3 to generate 2 with 217 loss of $\mathrm{KCl}$ and $\mathrm{PMe}_{3}$ but also suggested that another pathway 218 of hydride transfer or $\beta$-hydride elimination of an amidoborane 219 moiety from the cobalt center might be possible. Recent 220 literature suggests that the $\mathrm{KNH}_{2} \mathrm{BH}_{3}$ reagent may be 221 operating as a hydride source in this case. Weller and co222 workers have suggested that the amidoborane reagent $223 \mathrm{LiNMe}_{2} \mathrm{BH}_{3}$ likely functions as a simple hydride source as 224 opposed to forming an amidoborane intermediate followed by $225 \beta$-hydride elimination in a (PONOP) Rh system, ${ }^{49}$ and work by $226 \mathrm{Hill}$ and co-workers also finds $\beta$-elimination processes of group 2272 metal amidoborane complexes to be high in energy. ${ }^{47}$ The 228 resistance of 2 to undergo $\beta$-hydride elimination according to 229 DFT calculations (vide infra) suggests that $\mathrm{KNH}_{2} \mathrm{BH}_{3}$ may in 230 fact be operating as a hydride source in this case. The reaction 231 of 2 with excess $\mathrm{KNH}_{2} \mathrm{BH}_{3}$ in the presence of $\mathrm{PMe}_{3}$ also led to 232 the observation of $\mathbf{4}$ and other unidentified diamagnetic 233 species (Figure S19), suggesting that 2 can be further activated 234 by $\mathrm{KNH}_{2} \mathrm{BH}_{3}$. The exact mechanism of activation of each 235 species remains unclear, but the generation of a transient 236 dihydride species followed by reductive elimination is a 237 plausible pathway for the reduction of these species. This 238 reduction was found to be generalizable to other $\mathrm{Co}$ (III) 239 complexes with $\mathrm{KNH}_{2} \mathrm{BH}_{3}$ (see the Supporting Information). 240 Dehydrogenation of $A B$ with (Mes CCC)Co-py (1) and 241 ( $\left.{ }^{\mathrm{Mes}} \mathrm{CCC}\right) \mathrm{CoH}\left(\mathrm{NH}_{2} \mathrm{BH}_{3}\right)$ (2). Generally, homogeneous tran242 sition metal catalysts for the catalytic dehydrogenation of $\mathrm{AB}$ 243 fall into one of two categories referred to as Type I and II 244 catalysts as defined by Paul and co-workers (Scheme 3). ${ }^{50}$ 245 Type I catalysts typically form aminoborane $\left(\mathrm{NH}_{2} \mathrm{BH}_{2}\right)$ which 246 binds strongly to the metal center and polymerizes further,

Scheme 3. Types of Homogeneous AB Dehydrogenation Catalysts as Defined by Paul and Baker ${ }^{50}$

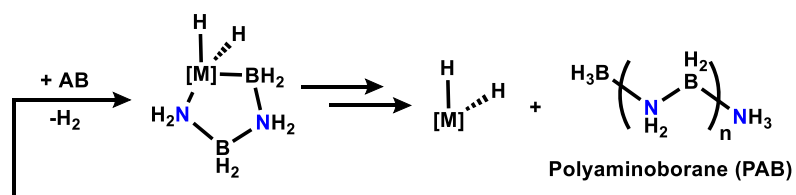

Tvpe I - Formation of oligomeric species

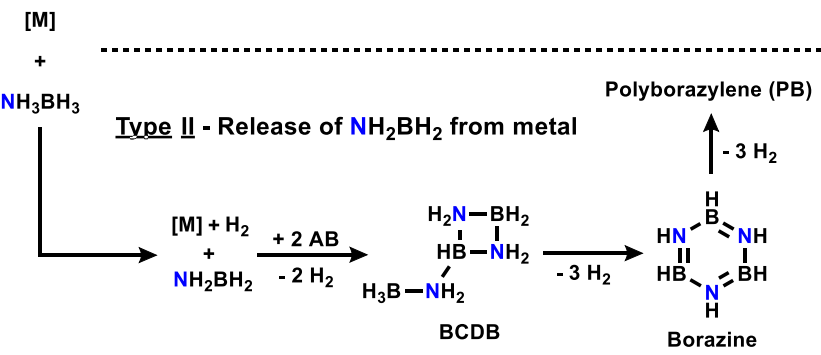

forming insoluble polymeric species and releasing 1 equiv of 247 $\mathrm{H}_{2}$ per $\mathrm{AB}$. Type II catalysts typically undergo formation of 248 $\mathrm{NH}_{2} \mathrm{BH}_{2}$ and release this highly reactive species from the metal 249 center, which then undergoes further off-metal oligomeriza- 250 tion/dehydrogenation to release $>1$ equiv of $\mathrm{H}_{2}$ per $\mathrm{AB}$. The 251 delineation between these two pathways is not always clear 252 because it is possible to release $\mathrm{NH}_{2} \mathrm{BH}_{2}$ from the metal center 253 while still having on-metal polymerization as the active 254 mechanism.

255

To test the catalytic competence of 1 toward $\mathrm{AB} 256$ dehydrogenation, $10 \mathrm{~mol} \% 1$ was reacted with $\mathrm{AB}$ at $60{ }^{\circ} \mathrm{C} 257$ in THF and tracked by ${ }^{11} \mathrm{~B}$ NMR spectroscopy over time 258 (Figure 4). The primary soluble products formed at the $259 \mathrm{f} 4$

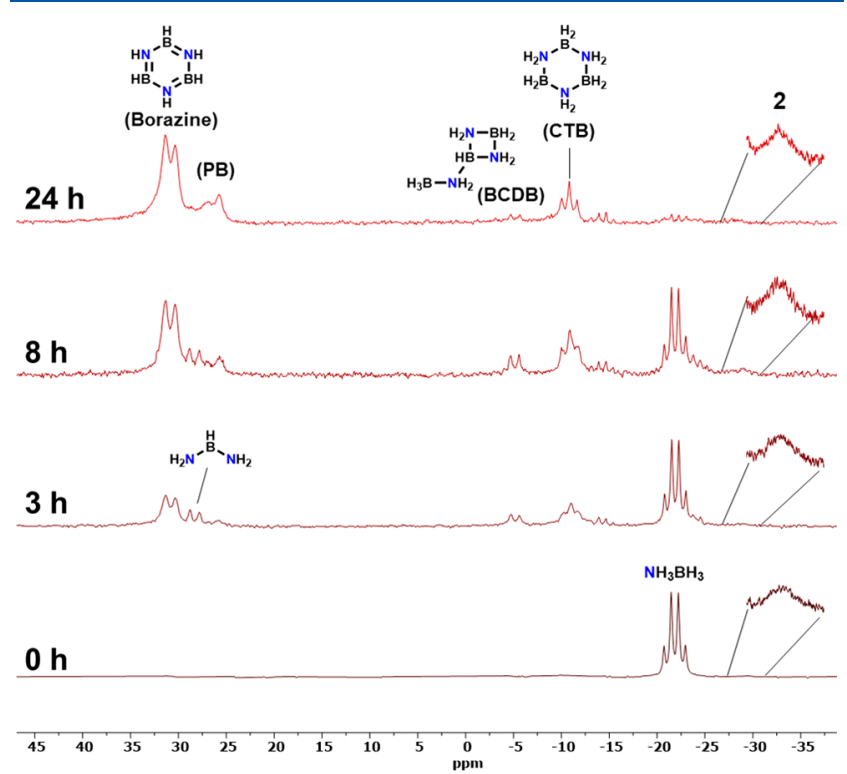

Figure 4. ${ }^{11} \mathrm{~B}$ NMR spectra of catalytic dehydrogenation of $\mathrm{AB}$ with $10 \mathrm{~mol} \% 1$ in THF at $60{ }^{\circ} \mathrm{C}$ over time.

beginning of the reaction were cyclotriborazane (CTB, ca. -11260 ppm), (B-(cyclodiborazanyl)aminoborohydride (BCDB, ca. 261 -5 ppm), borazine (ca. $30 \mathrm{ppm}$ ), and diaminoborane 262 $\left(\mathrm{BH}\left(\mathrm{NH}_{2}\right)_{2}\right.$, ca. $\left.28 \mathrm{ppm}\right) .^{21,22,51-55}$ As the reaction proceeded 263 the products skewed toward borazine and then polyborazylene 264 (PB) further upfield at ca. 25 ppm. ${ }^{51}$ As a control reaction, AB 265 was heated at $60{ }^{\circ} \mathrm{C}$ in THF in the absence of 1 resulting in 266 negligible conversion of $\mathrm{AB}$ to form a small amount of CTB. 267 The addition of excess $\mathrm{Hg}(0)$ did not affect the progression of 268 the reaction, suggesting that cobalt nanoparticles are not 269 responsible for the observed catalytic activity. ${ }^{56}$ These 270 reactions suggested that $A B$ is in fact catalytically dehydro- 271 genated by $\mathbf{1}$ and the reaction takes place in the homogeneous 272 phase. Preliminary studies also showed that $\mathbf{1}$ catalyzes the 273 dehydrogenation of DMAB and methylamine borane (Figures 274 S15 and S16 respectively), suggesting these type of cobalt 275 pincer complexes may prove broadly applicable in this field. 276

The BN products (mainly PB and borazine) observed by ${ }^{11} \mathrm{~B} 277$ NMR spectroscopy during catalytic dehydrogenation with $\mathbf{1} 278$ are suggestive of a mechanism which involves the formation of 279 $\mathrm{NH}_{2} \mathrm{BH}_{2}$ followed by the release of this species from the cobalt 280 center. Because of its reactivity, $\mathrm{NH}_{2} \mathrm{BH}_{2}$ is not practically 281 observed in solution; however, addition of cyclohexene to the 282 reaction allows for the trapping of the hydroborated cyclo- 283 hexene product $\left(\mathrm{Cy}_{2} \mathrm{BNH}_{2}\right) .{ }^{57}$ Running this trapping experi- 284 


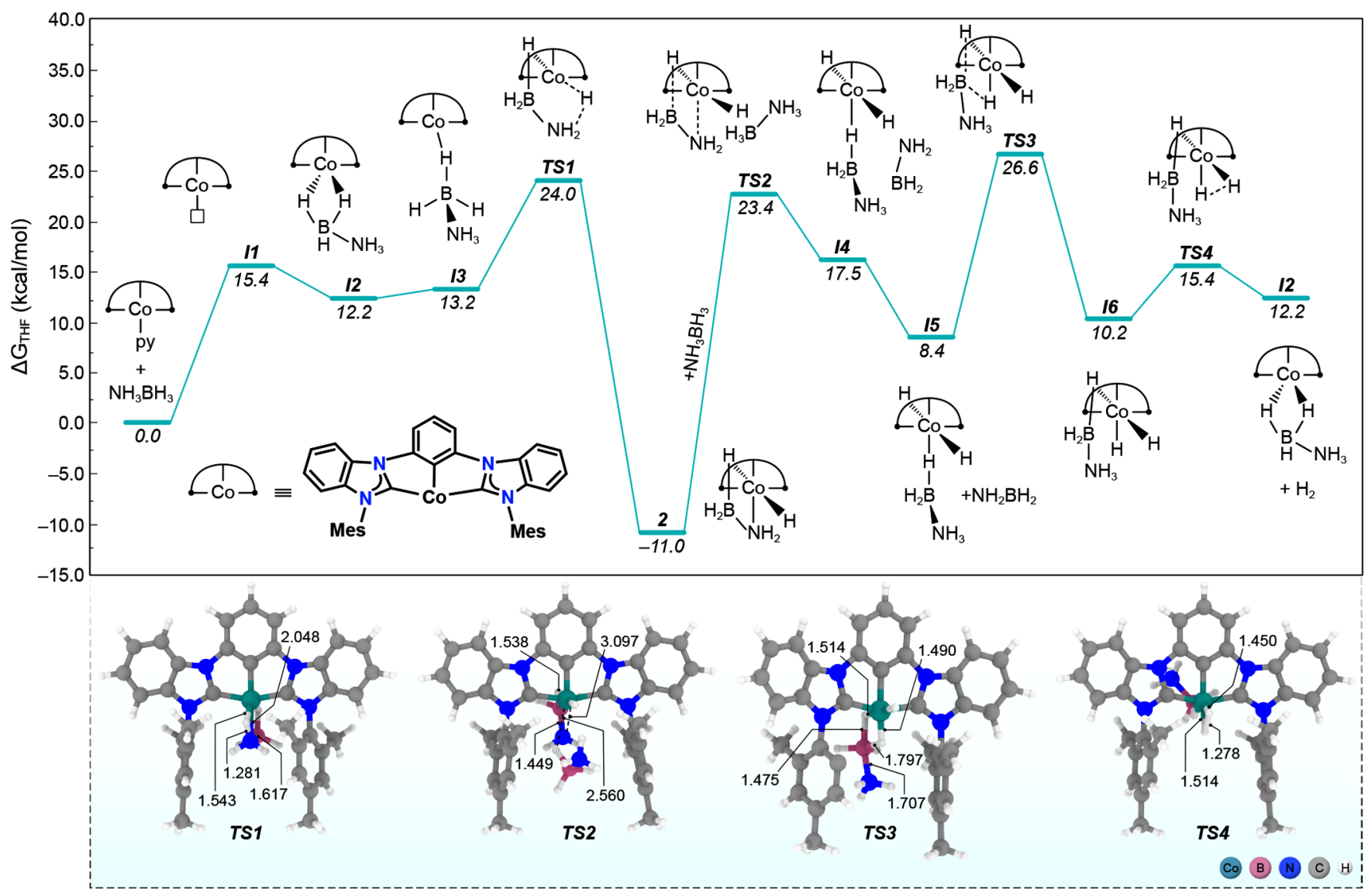

Figure 5. Top: calculated Gibbs energy profile in THF at $298 \mathrm{~K}$ and $1 \mathrm{~atm}$ for the formation of 2 starting from 1 and further release of $\mathrm{NH}_{2} \mathrm{BH}_{2}$ from 2. Bottom: optimized transition state structures with the relevant bond distances (in $\AA$ ).

285 ment under the catalytic conditions resulted in the formation 286 of the $\mathrm{Cy}_{2} \mathrm{BNH}_{2}$ species as confirmed by ${ }^{11} \mathrm{~B} \mathrm{NMR}$ 287 spectroscopy (Figure S11). Both the soluble BN-containing 288 species observed in the catalytic dehydrogenation of $A B$ and 289 the trapping of $\mathrm{NH}_{2} \mathrm{BH}_{2}$ suggest that $\mathbf{1}$ is acting as a Type II 290 catalyst (Scheme 3 ). However, under small-scale catalytic runs, 291 a non-negligible amount of precipitate was formed. Upon 292 scaling up of the reaction, characterization of this precipitate by 293 IR spectroscopy suggested the formation of poly294 (aminoborane) (PAB) (Figure S12). ${ }^{58,59}$ The formation of $295 \mathrm{PAB}$ suggests that $\mathbf{1}$ is acting as both a Type I and II catalyst 296 under these conditions. The amount of $\mathrm{H}_{2}$ per $\mathrm{AB}$ was 297 determined to be $1.7 \pm 0.1$ equiv with an inverted buret 298 apparatus (see Supporting Information). The amount of $\mathrm{H}_{2}$ 299 released is consistent with $\mathbf{1}$ acting as both types of $\mathrm{AB}$ 300 dehydrogenation catalyst.

301 Monitoring catalytic reactions utilizing $\mathbf{1}$ by ${ }^{1} \mathrm{H}$ and ${ }^{11} \mathrm{~B}$ 302 NMR spectroscopy reveals that $\mathbf{2}$ is formed within minutes in 303 THF and remains the primary observable cobalt species in 304 solution. To ensure that $\mathbf{2}$ was not simply a stable, off-pathway 305 product from the catalytic reaction, isolated $\mathbf{2}$ was employed in 306 the catalytic dehydrogenation of $\mathrm{AB}$. Reacting $10 \mathrm{~mol} \% 2$ with $307 \mathrm{AB}$ at $60{ }^{\circ} \mathrm{C}$ in $\mathrm{THF}$ at the same concentration for reactions 308 with 1 resulted in conversion of $\mathrm{AB}$ to form a similar soluble 309 product distribution (Figure S13), albeit at a slower rate (ca. $31024 \mathrm{vs} 48 \mathrm{~h}$ for full conversion). The isolation of $\mathrm{PAB}$ was not 311 achieved when starting from 2 , which may rely on a sufficient 312 concentration of $\mathrm{NH}_{2} \mathrm{BH}_{2}$ to be competitive (vide infra). 313 These results suggest that $\mathbf{2}$ is either one of the active species or goes on to form one of the active species in solution. 314 Heating 2 at $60{ }^{\circ} \mathrm{C}$ in the absence of $\mathrm{AB}$ in THF- $d_{8}$ revealed 315 no appreciable conversion of $\mathbf{2}$ to other complexes. This 316 suggests that $\beta$-hydride elimination directly from $\mathbf{2}$ is not a 317 likely pathway for the release of $\mathrm{NH}_{2} \mathrm{BH}_{2}$ from the cobalt 318 center in the absence of additional $\mathrm{AB}$.

The competing pathways for $\mathrm{AB}$ dehydrogenation under the 320 catalytic conditions frustrated efforts to perform kinetic 321 analyses on this system. Hence, we turned our attention to 322 DFT to try and provide insight into possible pathways starting 323 from 2 that would match experimental observations. 324

DFT Studies: Formation of $\mathbf{2}$ and Further Reactivity 325 of 2 with $\mathrm{AB}$. DFT studies at the wb97xD level sought to 326 provide further insight on the reaction mechanism for the 327 initial $\mathrm{N}-\mathrm{H}$ activation process of $\mathrm{AB}$ onto $\mathbf{1}$ to form 2 . The 328 lowest Gibbs energy pathway obtained for this process is 329 presented in Figure 5. The reaction begins with the $330 \mathrm{fs}$ dissociation of the pyridine ligand from 1 to form intermediate 331 I1, followed by the association of $\mathrm{AB}$ through an $\eta^{2} \mathrm{~B}-\mathrm{H} 332$ interaction to afford I2. This latter complex, which lies 12.2333 $\mathrm{kcal} \mathrm{mol}^{-1}$ above the separate reactants, subsequently under- 334 goes rearrangement to form $\eta^{1}$ species I3, which is ready for 335 $\mathrm{N}-\mathrm{H}$ activation. The $\mathrm{N}-\mathrm{H}$ activation step across the Co 336 center is achieved through TS1 and results in structurally 337 characterized hydride-amidoborane complex 2 . The calculated 338 barrier for the overall process is $24.0 \mathrm{kcal} \mathrm{mol}^{-1}$ in THF, which 339 is consistent with the reaction proceeding at room temper- 340 ature. DFT calculations also predict the formation of 2 to be 341 exergonic by $-11.0 \mathrm{kcal} \mathrm{mol}^{-1}$, which is in line with the 342 
343 stability of the hydride-amidoborane complex formed. Other 344 reaction pathways considered for the formation of $\mathbf{2}$ included 345 the activation of the $\mathrm{N}-\mathrm{H}$ bond from $\mathbf{1}$ (with the pyridine 346 coordinated to $\mathrm{Co}$ ) and the $\mathrm{B}-\mathrm{H}$ activation of $\mathrm{AB}$ from $\mathrm{I} 3$ 347 (see Figures S21 and S22 respectively). Both alternative paths 348 were discarded based on their significantly high energy barriers 349 (50.1 and $35.2 \mathrm{kcal} \mathrm{mol}^{-1}$, respectively). Notably, the fact that 350 the $\mathrm{B}-\mathrm{H}$ activation of $\mathrm{AB}$ was $11.2 \mathrm{kcal} \mathrm{mol}^{-1}$ higher in energy 351 than the $\mathrm{N}-\mathrm{H}$ activation via TS1 is in good agreement with 352 the deuteration studies.

353 The vibrational modes of the optimized structure of 2 were 354 calculated and can be found in Figure S23. The Co-H 355 stretching frequency was calculated to be $1968 \mathrm{~cm}^{-1}$, which is 356 in reasonably good agreement with the reported experimental 357 peak at ca. $1860 \mathrm{~cm}^{-1}$. The calculated $\mathrm{BH}_{2}$ stretching 358 frequencies are 2506 and $2554 \mathrm{~cm}^{-1}$ which also match 359 moderately well to the experimental $\mathrm{BH}_{2}$ stretching 360 frequencies at ca. $2400 \mathrm{~cm}^{-1}$. The asymmetric and symmetric $361 \mathrm{NH}_{2}$ stretching frequencies were calculated to be 3709 and $3623624 \mathrm{~cm}^{-1}$ respectively, compared to the experimental 363 stretching frequencies of 3434 and $3364 \mathrm{~cm}^{-1}$. The Co$364 \mathrm{BH}_{\text {(Bridging) }}$ stretching frequency was calculated to be 1713 $365 \mathrm{~cm}^{-1}$; however, this peak could not be definitively assigned in 366 the experimental spectra (vide supra).

367 In order to shed light on the nature of the bonding of the 368 amidoborane fragment in 2 , natural bond orbital (NBO) and 369 second-order perturbation theory (SOPT) analyses were 370 performed to ascertain the main donor-acceptor interactions 371 involved in the $\mathrm{Co}-\mathrm{N}, \mathrm{Co}-\mathrm{H}(\mathrm{B})$, and $\mathrm{B}-\mathrm{N}$ bonds (Figure 6). 372 These analyses revealed that the most important interaction
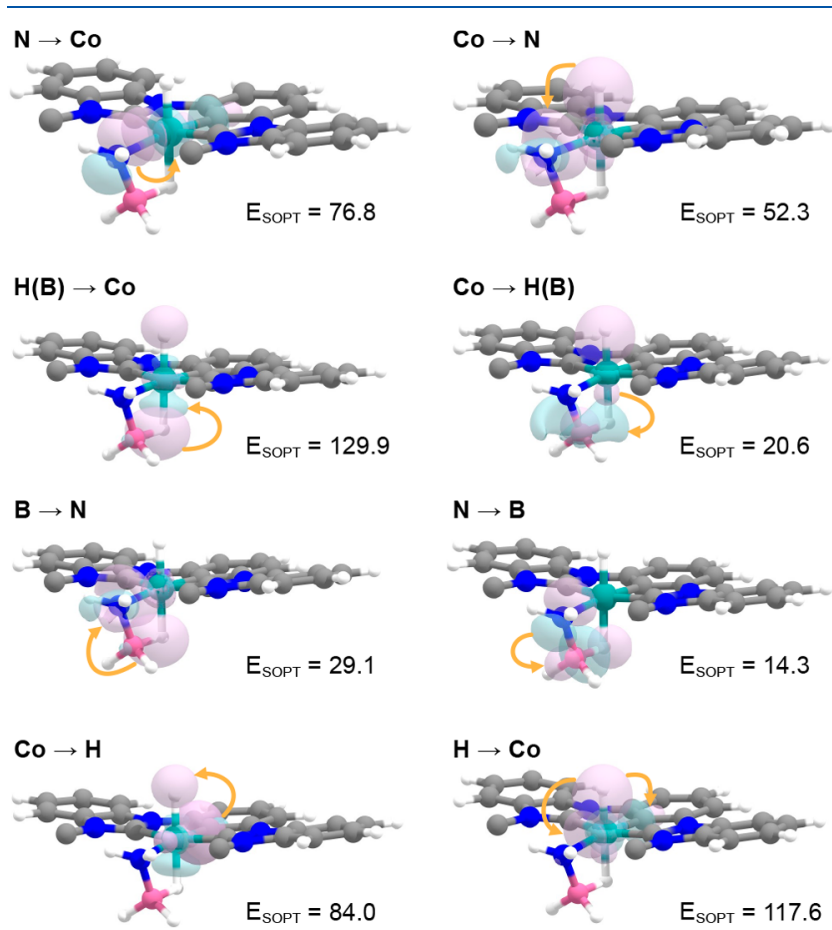

Figure 6. NBO representation (isovalue $=0.08 \mathrm{e}^{-} / \mathrm{bohr}^{3}$ ) of the main donor-acceptor interactions involved in the $\mathrm{Co}-\mathrm{N}, \mathrm{Co}-\mathrm{H}(\mathrm{B})$, and $\mathrm{B}-\mathrm{N}$ bonds obtained from SOPT. The energy computed for each of these interactions, $E_{\mathrm{SOPT}}$, is shown in $\mathrm{kcal} / \mathrm{mol}$. Orange arrows indicate the electron flow from the donor to the acceptor NBO. The mesityl flanking groups have been omitted for clarity. The color code is the same as that in Figure 5. between $\mathrm{Co}$ and the $\mathrm{N}$ from amidoborane arises from the 373 electron donation from a N 2p orbital to an empty sd-sp 374 hybrid orbital constituted by $\mathrm{Co}$ and the aryl $\mathrm{C}$ atom of the 375 ligand and from the donation from a hybrid sd-s orbital from 376 the $\mathrm{Co}-\mathrm{H}$ bond to an empty sp orbital from N. The 377 interaction between $\mathrm{Co}$ and $\mathrm{H}(\mathrm{B})$ was found to be mostly 378 governed by the electron donation from the hybrid sp-s 379 orbital of the $\mathrm{B}-\mathrm{H}$ bond to the antibonding sd-s hybrid 380 orbital from $\mathrm{Co}-\mathrm{H}$, and the backdonation from the above sd- 381 $\mathrm{s}$ bonding orbital from $\mathrm{Co}-\mathrm{H}$ to an empty sp orbital from B. 382 Finally, the main donor-acceptor interactions within the 383 amidoborane fragment correspond to the electron donation 384 from the bonding sp-s orbital of $\mathrm{B}-\mathrm{H}$ to the above empty sp 385 orbital from $\mathrm{N}$, and the backdonation from the above filled N- 386 $2 \mathrm{p}$ orbital to the $\mathrm{sp}-\mathrm{s}$ antibonding orbital of $\mathrm{B}-\mathrm{H}$. For details 387 of the exact composition of the NBOs involved in these 388 donor-acceptor interactions, see Table S1.

389

Because employing both $\mathbf{1}$ and $\mathbf{2}$ as a catalyst showed $\mathbf{2}$ as 390 the primary observable cobalt species, we next sought to use 391 DFT to elucidate a plausible reaction mechanism for $\mathrm{NH}_{2} \mathrm{BH}_{2} 392$ release from 2 to form the products consistent with a Type II 393 catalyst. To this end, DFT calculations of the reaction of $\mathbf{2}$ with 394 $\mathrm{AB}$ were conducted, obtaining the reaction pathway 395 summarized in Figure 5. Interestingly, the release of 396 $\mathrm{NH}_{2} \mathrm{BH}_{2}$ from 2 proved to be energetically unfavorable unless 397 an $\mathrm{AB}$ molecule was in proximity to the Co center to assist the 398 process. This is consistent with the fact that no elimination of 399 $\mathrm{NH}_{2} \mathrm{BH}_{2}$ is observed when 2 is heated in the absence of $\mathrm{AB} .400$ Calculations also show that when $\mathrm{AB}$ is present the release of 401 $\mathrm{NH}_{2} \mathrm{BH}_{2}$ takes place via TS2 with an activation energy of 34.4402 $\mathrm{kcal} \mathrm{mol}^{-1}$, in line with catalytic turnover occurring at $60{ }^{\circ} \mathrm{C}$ in 403 THF. During TS2, both Co-N and B- $\mathrm{H}_{\text {(Bridging) }}$ bonds (3.097 404 and $1.513 \AA$, respectively) are cleaved to release $\mathrm{NH}_{2} \mathrm{BH}_{2}$ with 405 the concomitant coordination of the nearby $\mathrm{AB}$ (Co-B: 3.455406 A) to yield I5.

407

Upon elimination of $\mathrm{NH}_{2} \mathrm{BH}_{2}$ from I4, the more stable (9.1 408 $\mathrm{kcal} \mathrm{mol}^{-1}$ lower than I4) trans-dihydride species with an $\eta^{1} 409$ $\mathrm{B}-\mathrm{H}$ interaction (I5) is formed. This species subsequently 410 undergoes a trans-to-cis isomerization through TS3 where the 411 $\mathrm{BH}_{2} \mathrm{NH}_{3}$ moiety is transferred to one of the hydrides to yield 412 I6. This step requires a relative energy barrier of $18.2 \mathrm{kcal} 413$ $\mathrm{mol}^{-1}$ and is slightly endergonic by $1.8 \mathrm{kcal} \mathrm{mol}^{-1}$. From I6, 414 the reductive elimination of $\mathrm{H}_{2}$ occurs via TS4 with a relative 415 energy barrier of only $5.2 \mathrm{kcal} \mathrm{mol}^{-1}$. The result of this last 416 transformation is $\mathbf{I} \mathbf{3}$ which can again undergo $\mathrm{N}-\mathrm{H}$ activation 417 to yield 2. The highest energy point of the diagram is TS3 at 418 $37.6 \mathrm{kcal} / \mathrm{mol}$ from 2 , which is consistent with catalytic 419 turnover occurring at $60{ }^{\circ} \mathrm{C}$ in THF. Overall, the mechanism 420 depicted in Figure 5 accounts for the release of 1 equiv of $\mathrm{H}_{2} 421$ and $\mathrm{NH}_{2} \mathrm{BH}_{2}$ from 2, which was confirmed by trapping 422 experiments using cyclohexene. A process in which the 423 $\mathrm{NH}_{2} \mathrm{BH}_{3}{ }^{-}$fragment of 2 stays intact with reactivity occurring 424 solely at the hydride is also a possibility but was not found 425 computationally.

Finally, DFT calculations were performed to propose a 427 plausible mechanism for the oligomerization of $\mathrm{AB}$ starting 428 from 2 (Figure 7). Starting from this species, the association of $429 \mathrm{f} 7$ $\mathrm{NH}_{2} \mathrm{BH}_{2}$ previously formed to yield $\mathbf{I} 7$ was found to be slightly 430 endergonic (by ca. $1 \mathrm{kcal} \mathrm{mol}^{-1}$ ). This complex can then 431 undergo $\mathrm{N}-\mathrm{B}$ bond formation and $\mathrm{B}-\mathrm{H}$ bond formation with 432 the existing $\mathrm{B}-\mathrm{H}_{\text {(Bridging) }}$ of the amidoborane fragment in a 433 concerted process via TS5 leading to on-metal oligomeric 434 species I8. Overall, the oligomerization of $\mathrm{AB}$ requires an 435 


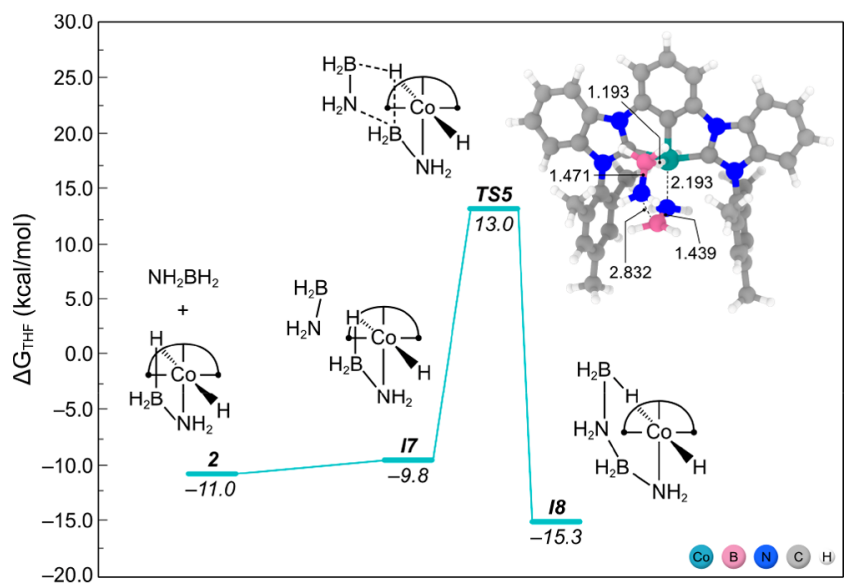

Figure 7. Calculated Gibbs energy profile in THF at $298 \mathrm{~K}$ and $1 \mathrm{~atm}$ for the oligomerization of $\mathrm{AB}$ on 2 .

436 energy barrier of $24.0 \mathrm{kcal} \mathrm{mol}^{-1}$ and is exergonic by ca. 4.3 $437 \mathrm{kcal} \mathrm{mol}^{-1}$. Further oligomerization steps are postulated to 438 involve the insertion of additional $\mathrm{NH}_{2} \mathrm{BH}_{2}$ molecules into the 439 growing oligomeric chain. Although isolation of $\mathrm{PAB}$ was not 440 possible when starting from 2 , this suggested oligomerization 441 process relies on a sufficient concentration of $\mathrm{NH}_{2} \mathrm{BH}_{2}$ in 442 solution. ${ }^{60}$ Given the higher activity when employing $\mathbf{1}$, it is 443 possible that this results in a higher concentration of $\mathrm{NH}_{2} \mathrm{BH}_{2}$ 444 in solution which can react with 2 .

\section{${ }_{445}$ CONCLUSION}

$446 \mathrm{Co}(\mathrm{I})$ pincer complex 1 reported herein represents a rare 447 example of a homogeneous catalyst for the dehydrogenation of $448 \mathrm{AB}$. The formation of soluble (borazine and polyborazylene) 449 and insoluble (poly(aminoborane)) BN-containing products 450 suggests the existence of competing mechanisms for the 451 dehydrogenation/dehydropolymerization of $\mathrm{AB}$ on $\mathbf{1}$. Reaction 452 of $\mathbf{1}$ with $\mathrm{AB}$ yielded complex $\mathbf{2}$, the first characterized hydride453 amidoborane complex on a late transition metal. Isotopic 454 labeling and DFT studies revealed that $\mathbf{2}$ was formed via an $455 \mathrm{~N}-\mathrm{H}$ activation process of $\mathrm{AB}$ at the Co center of 1 . In 456 addition, computational studies outline likely pathways of 457 activation for 2 to produce the experimentally observed $\mathrm{BN}$ 458 containing species. The knowledge generated herein is 459 expected to inspire the design of well-defined cobalt pincer 460 complexes to provide further insights into the dehydrogenation 461 and dehydropolymerization of $A B$ and other amine boranes.

\section{EXPERIMENTAL SECTION}

463 General Considerations. All manipulations of air- and moisture464 sensitive compounds were carried out in the absence of water and 465 dioxygen in an MBraun inert atmosphere drybox under a dinitrogen 466 atmosphere except where specified otherwise. The MBraun drybox 467 was equipped with $\mathrm{a}-35{ }^{\circ} \mathrm{C}$ freezer for cooling samples and 468 crystallizations. All glassware was oven-dried for a minimum of $8 \mathrm{~h}$ 469 and cooled in an evacuated antechamber prior to use in the drybox. 470 Solvents for sensitive manipulations were dried and deoxygenated on 471 a Glass Contour System (SG Water USA, Nashua, NH) and stored 472 over 4 A molecular sieves purchased from Strem following literature 473 procedure prior to use. ${ }^{61}$ NMR solvents $\left(\mathrm{C}_{6} \mathrm{D}_{6}\right.$ and THF- $\left.d_{8}\right)$ were 474 purchased from Cambridge Isotope Laboratories and were degassed 475 and stored over $4 \AA$ molecular sieves prior to use. Celite 545 (J. T. 476 Baker) was dried in a Schlenk flask for $24 \mathrm{~h}$ under dynamic vacuum 477 while heating to at least $150{ }^{\circ} \mathrm{C}$ prior to use in a glovebox. Ammonia 478 borane was purchased from Sigma and filtered through Celite with 479 THF before use. Dimethylamine borane (DMAB) was purchased from Sigma and used as received. The deuterated isotopologues 480 $\mathrm{NH}_{3} \mathrm{BD}_{3}$ and $\mathrm{ND}_{3} \mathrm{BH}_{3}$ were synthesized according to a literature 481 procedure. $^{29}$ ( $\left.{ }^{\mathrm{Mes}} \mathrm{CCC}\right) \mathrm{Co}$-py (1), ${ }^{35}$ ( $\left.{ }^{\mathrm{Mes}} \mathrm{CCC}\right) \mathrm{CoHClPMe}_{3}$ (3), ${ }^{33}{ }_{482}$ methylamine borane, ${ }^{62}$ and $\mathrm{KNH}_{2} \mathrm{BH}_{3}{ }^{63}$ were synthesized according 483 to literature procedures.

${ }^{1} \mathrm{H},{ }^{13} \mathrm{C}$, and ${ }^{11} \mathrm{~B}$ NMR spectra were recorded at room temperature 485 on a Varian spectrometer operating at $500 \mathrm{MHz}\left({ }^{1} \mathrm{H}\right.$ NMR), 126486 $\mathrm{MHz}\left({ }^{13} \mathrm{C} \mathrm{NMR}\right)$, and $128 \mathrm{MHz}\left({ }^{11} \mathrm{~B}\right.$ NMR $)$ and referenced to the 487 residual solvent peaks and $\mathrm{BF}_{3} \cdot \mathrm{Et}_{2} \mathrm{O}(\delta 0 \mathrm{ppm})$ for ${ }^{11} \mathrm{~B}$. Solid-state 488 infrared spectra were recorded using a PerkinElmer Frontier FT-IR 489 spectrophotometer equipped with a KRS5 thallium bromide/iodide 490 universal attenuated total reflectance accessory. Electrospray ioniza- 491 tion mass spectrometry (ESI) was recorded on a Water Q-TOF 492 Ultima ESI instrument in the Mass Spectrometry Laboratory at the 493 University of Illinois at Urbana-Champaign (UIUC).

Crystallography. X-ray crystallography was performed at the 495 George L. Clark X-ray Facility at UIUC. Single-crystal X-ray 496 diffraction data were collected with the use of multimirror 497 monochromatized Mo K $\alpha$ radiation $(0.71073 \AA$ ) at $100 \mathrm{~K}$ on a 498 Bruker D8 Venture diffractometer equipped with a Photon 100499 detector. Combinations of $0.5^{\circ} \varphi$ and $\omega$ scans were used to collect the 500 data. The collection, cell refinement, and integration of intensity data 501 were carried out with the APEX2 software. ${ }^{64}$ A multiscan absorption 502 correction was performed using SADABS. ${ }^{65}$ The structure was solved 503 with $\mathrm{XT}^{66}$ and refined with the full-matrix least-squares SHELXL ${ }^{67} 504$ program within the Olex $2^{68}$ refinement GUI. Metrical parameters are 505 available in Table $S 1$.

Preparation of $\left({ }^{\mathrm{Mes}} \mathrm{CCC}\right) \mathrm{CoH}\left(\mathrm{NH}_{2} \mathrm{BH}_{3}\right)$ (2). In the glovebox, a 20507 $\mathrm{mL}$ scintillation vial was charged with $\left({ }^{\mathrm{Mes}} \mathrm{CCC}\right) \mathrm{Co}$-py $(20.5 \mathrm{mg}, 0.03508$ mmol, 1.0 equiv), a magnetic stir bar, and ca. $3 \mathrm{~mL}$ of THF. To this 509 stirring solution, $\mathrm{NH}_{3} \mathrm{BH}_{3}(1.0 \mathrm{mg}, 0.033 \mathrm{mmol}, 1.1$ equiv) was added 510 with ca. $3 \mathrm{~mL}$ of THF resulting in a color change from dark red/ 511 brown to amber within minutes. This solution was allowed to stir for 512 $2 \mathrm{~h}$, and then volatiles were removed. The brown residue was washed 513 with hexanes $(4 \times 2 \mathrm{~mL})$ dissolved in benzene, and then filtered 514 through Celite. This solution was frozen, and then volatiles were 515 removed to yield ( $\left.{ }^{\mathrm{Mes}} \mathrm{CCC}\right) \mathrm{CoH}\left(\mathrm{NH}_{2} \mathrm{BH}_{3}\right)$ as a light brown powder 516 $(17.8 \mathrm{mg}, 93 \%)$. Crystals suitable for X-ray diffraction were grown 517 from the diffusion of pentane into a solution of $2 .{ }^{1} \mathrm{H}$ NMR (500 518 $\left.\mathrm{MHz}, \mathrm{C}_{6} \mathrm{D}_{6}\right) \delta 7.77(\mathrm{~d}, J=8.1 \mathrm{~Hz}, 2 \mathrm{H}), 7.59(\mathrm{~d}, J=7.8 \mathrm{~Hz}, 2 \mathrm{H}), 7.42519$ $(\mathrm{t}, J=7.7 \mathrm{~Hz}, 1 \mathrm{H}), 7.05(\mathrm{t}, J=7.7 \mathrm{~Hz}, 2 \mathrm{H}), 6.87(\mathrm{t}, J=7.7 \mathrm{~Hz}, 2 \mathrm{H}), 520$ $6.69(\mathrm{~s}, 2 \mathrm{H}), 6.56(\mathrm{~s}, 2 \mathrm{H}), 6.52(\mathrm{~d}, J=8.0 \mathrm{~Hz}, 2 \mathrm{H}), 2.20(\mathrm{~s}, 6 \mathrm{H}), 2.01521$ (s, 6H), $1.90(\mathrm{~s}, 6 \mathrm{H}), 1.33$ (br s, $\left.2 \mathrm{H}, \mathrm{Co}-\mathrm{B} \mathrm{H}_{\text {(Terminal })}\right) 0.12(\mathrm{~s}, 2 \mathrm{H}, 522$ $\left.\mathrm{Co}-\mathrm{NH}_{2}\right),-8.76\left(\mathrm{~s}, 1 \mathrm{H}, \mathrm{Co}-\mathrm{BH}_{\text {(Bridging })}\right),-15.03(\mathrm{~s}, 1 \mathrm{H}, \mathrm{Co}-\mathrm{H}) .523$ ${ }^{13} \mathrm{C}$ NMR $\left(126 \mathrm{MHz}, \mathrm{C}_{6} \mathrm{D}_{6}\right) \delta 208.27\left(\mathrm{Co}-\mathrm{C}_{\mathrm{NHC}}\right), 172.99(\mathrm{Co}-524$ $\left.C_{\text {Aryl }}\right), 148.24,139.20,138.17,137.20,136.61,132.17,131.70,130.00,525$ $129.37,123.03,122.39,121.80,111.01,109.75,107.81,20.94,18.68,526$ 18.66. ${ }^{11} \mathrm{~B}$ NMR $\left(128 \mathrm{MHz}, \mathrm{C}_{6} \mathrm{D}_{6}\right) \delta-28.1$. IR $(\mathrm{KBr}): \nu\left(\mathrm{cm}^{-1}\right)=527$ $3434(\mathrm{~m}, \mathrm{NH}), 3364(\mathrm{w}, \mathrm{NH}), 3100-2800(\mathrm{~m}, \mathrm{CH}), 2415(\mathrm{~m}, 528$ $\left.\mathrm{BH}_{(\text {Terminal })}\right), 2344\left(\mathrm{~m}, \mathrm{BH}_{(\text {Terminal })}\right), 1862(\mathrm{~m}, \mathrm{Co}-\mathrm{H})$. HRMS (ESI), 529 calcd for $\mathrm{C}_{38} \mathrm{H}_{34} \mathrm{CoN}_{4}\left[\mathrm{M}-\mathrm{NH}_{2} \mathrm{BH}_{3}\right]^{+}$: 605.2115. Found 605.2112. 530

Formation of Deuterated Analogues of 2. In the glovebox, a 531 $20 \mathrm{~mL}$ scintillation vial was charged with ( $\left.{ }^{\mathrm{Mes}} \mathrm{CCC}\right) \mathrm{Co}$-py (1) (10.2 532 $\mathrm{mg}, 0.015 \mathrm{mmol}, 1.0$ equiv), a magnetic stir bar, and ca. $2 \mathrm{~mL}$ of THF. 533 To this stirring solution, the deuterated analogue $\left(\mathrm{NH}_{3} \mathrm{BD}_{3}\right.$ or 534 $\mathrm{ND}_{3} \mathrm{BH}_{3}, 0.0165 \mathrm{mmol}, 1.1$ equiv) was added with ca. $2 \mathrm{~mL}$ of THF 535 resulting in a color change from dark red/brown to amber within 536 minutes. This solution was allowed to stir for $2 \mathrm{~h}$ and then volatiles 537 were removed. The brown residue was washed with hexanes $(3 \times 1538$ $\mathrm{mL})$, dissolved in benzene, and then filtered through Celite. This 539 solution was frozen, and then volatiles were removed to yield 540 ( $\left.{ }^{\text {Mes }} \mathrm{CCC}\right) \mathrm{CoH}\left(\mathrm{NH}_{2} \mathrm{BD}_{3}\right)$ and $\left({ }^{\text {Mes }} \mathrm{CCC}\right) \mathrm{CoD}\left(\mathrm{ND}_{2} \mathrm{BH}_{3}\right)$ as light 541 brown powders in ca. $90 \%$ yield.

Catalytic Dehydrogenation Reactions. In the glovebox, a 543 quartz J. Young NMR tube was charged with $\left({ }^{\mathrm{Mes}} \mathrm{CCC}\right) \mathrm{Co}$-py $(2.0544$ $\mathrm{mg}, 0.003 \mathrm{mmol}, 0.10$ equiv) or $\left({ }^{\mathrm{Mes}} \mathrm{CCC}\right) \mathrm{CoH}\left(\mathrm{NH}_{2} \mathrm{BH}_{3}\right)(1.9 \mathrm{mg}, 545$ $0.003,0.10$ equiv) and $600 \mu \mathrm{L}$ of THF of a $0.05 \mathrm{M} \mathrm{AB}$ solution (0.9 546 $\mathrm{mg}, 0.03 \mathrm{mmol}, 1.0$ equiv). The tube was sealed and then brought out 547 of the glovebox to heat in a $60{ }^{\circ} \mathrm{C}$ oil bath. The progress of the 548 reaction was tracked over time by ${ }^{11} \mathrm{~B}$ NMR. 
550 Mercury Drop Test Reaction. In the glovebox, a quartz J. Young $551 \mathrm{NMR}$ tube was charged with $\left({ }^{\mathrm{Mes}} \mathrm{CCC}\right) \mathrm{Co}-\mathrm{py}(2.0 \mathrm{mg}, 0.003 \mathrm{mmol}$, 5520.10 equiv), and $600 \mu \mathrm{L}$ of THF of a $0.05 \mathrm{M} \mathrm{AB}$ solution $(0.9 \mathrm{mg}$, $5530.03 \mathrm{mmol}, 1.0$ equiv). One drop of $\mathrm{Hg}(0)$ was added to the tube, and 554 the tube was then sealed before being brought out of the glovebox to 555 heat in a $60{ }^{\circ} \mathrm{C}$ oil bath. The reaction was agitated about every hour 556 to ensure contact of possible nanoparticles with $\mathrm{Hg}(0)$. The progress 557 of the reaction was tracked over time by ${ }^{11} \mathrm{~B}$ NMR.

558 Cyclohexene Trapping Experiment. In the glovebox, a quartz J. 559 Young NMR tube was charged with $\left({ }^{\mathrm{Mes}} \mathrm{CCC}\right) \mathrm{Co}-\mathrm{py}(2.0 \mathrm{mg}, 0.003$ $560 \mathrm{mmol}, 0.10$ equiv), $600 \mu \mathrm{L}$ of THF of a $0.05 \mathrm{M} \mathrm{AB}$ solution $(0.9 \mathrm{mg}$, $5610.03 \mathrm{mmol}, 1.0$ equiv), and cyclohexene (49.3 mg, $0.6 \mathrm{mmol}, 20$ 562 equiv). The tube was sealed and then brought out of the glovebox to 563 heat in a $60^{\circ} \mathrm{C}$ oil bath. The progress of the reaction was tracked over 564 time by ${ }^{11} \mathrm{~B}$ NMR spectroscopy.

565 Gas Evolution Reaction. In the glovebox, a $20 \mathrm{~mL}$ storage vessel 566 was charged with ( $\left.{ }^{\mathrm{Mes}} \mathrm{CCC}\right) \mathrm{Co}-\mathrm{py}(6.8 \mathrm{mg}, 0.01 \mathrm{mmol}, 0.05$ equiv), $567 \mathrm{AB}$ (6.2 mg, $0.20 \mathrm{mmol}, 1.0$ equiv), and $4.0 \mathrm{~mL}$ of THF. The vessel 568 was sealed, removed from the glovebox, attached to the gas evolution 569 setup as seen in Figure S17, and heated at $60{ }^{\circ} \mathrm{C}$ in a heating block. 570 The reaction was run in triplicate to determine $1.7 \pm 0.1$ equiv of $\mathrm{H}_{2}$ 571 was released per $\mathrm{AB}$.

572 Reaction of ( ${ }^{\text {Mes }} \mathrm{CCC}$ ) CoHCIPMe ${ }_{3}$ (3) with $\mathrm{KNH}_{2} \mathrm{BH}_{3}$. In the 573 glovebox, a $20 \mathrm{~mL}$ scintillation vial was charged with $\left({ }^{\mathrm{Mes}} \mathrm{CCC}\right)$ $574 \mathrm{CoHClPMe}_{3}$ (10.0 mg, $0.014 \mathrm{mmol}, 1.0$ equiv), $\mathrm{KNH}_{2} \mathrm{BH}_{3}(1.0 \mathrm{mg}$, 5750.014 mmol, 1.0 equiv), a magnetic stir bar, and ca. $5 \mathrm{~mL}$ of THF. 576 This solution was stirred at ambient temperature for ca. $15 \mathrm{~min}$, and 577 then volatiles were removed. This residue was dissolved in $\mathrm{C}_{6} \mathrm{D}_{6}$ and 578 then eluted through Celite into an NMR tube.

579 Reaction of ( $\left.{ }^{\text {Mes }} \mathrm{CCC}\right) \mathrm{CoH}\left(\mathrm{NH}_{2} \mathrm{BH}_{3}\right)$ (2) with $\mathrm{KNH}_{2} \mathrm{BH}_{3}$. In the 580 glovebox, a $20 \mathrm{~mL}$ scintillation vial was charged with ( $\left.{ }^{\mathrm{Mes}} \mathrm{CCC}\right)$ $581 \mathrm{CoH}\left(\mathrm{NH}_{2} \mathrm{BH}_{3}\right)$ (9.5 mg, $0.015 \mathrm{mmol}, 1.0$ equiv), $\mathrm{PMe}_{3}(1 \mathrm{M}$ in THF, 58210 equiv), a magnetic stir bar, and ca. $5 \mathrm{~mL}$ of THF. After stirring for $5835 \mathrm{~min}, \mathrm{KNH}_{2} \mathrm{BH}_{3}(1.0 \mathrm{mg}, 0.014 \mathrm{mmol}, 10.0$ equiv) was transferred 584 to the reaction vial with THF (ca. $1 \mathrm{~mL}$ ) and stirred at ambient 585 temperature for an additional $30 \mathrm{~min}$. Volatiles were removed, and 586 then the residue was dissolved in $\mathrm{C}_{6} \mathrm{D}_{6}$ and eluted through Celite into 587 an NMR tube.

588 Computational Details. DFT calculations were carried out using 589 the dispersion-corrected hybrid exchange-correlation functional $590 \mathrm{wB} \mathrm{XXD}^{69}$ and the Gaussian09 software. ${ }^{70}$ To describe the electrons 591 of $\mathrm{B}, \mathrm{C}$, and $\mathrm{H}$ atoms, the $6-31 \mathrm{G}(\mathrm{d}, \mathrm{p})$ basis set with polarization 592 functions was employed, while the same basis set with added diffuse 593 functions, i.e., 6-31+G(d,p), was used in the description of the more 594 electronegative $\mathrm{N}$ atoms. IN contrast, Co electrons were represented 595 with the Stuttgart/Dresden effective core potential with added $f$ 596 polarization functions (exponent: 2.780). ${ }^{71}$ The geometry of the 597 stationary points was optimized in vacuum without imposing any 598 constraint. The nature of these points was further assessed by means 599 of vibrational frequency calculations, which confirmed that energy 600 minima had only real frequencies, while transition states had only one 601 single imaginary frequency. In addition, the latter were confirmed to 602 connect the expected reaction intermediates by relaxing the transition 603 state geometry following the eigenvector associated to the imaginary 604 frequency.

605 The effect of the solvent employed in experiments (THF, $\varepsilon=7.52$ ) 606 was introduced by performing single-point calculations on the 607 optimized geometries in vacuum using the SMD solvation model. ${ }^{72}$ 608 Gibbs energies in THF were calculated by adding to the potential 609 energies in solution the Gibbs energy corrections calculated in 610 vacuum at the experimental temperature of $298 \mathrm{~K}$ and $1 \mathrm{~atm}$.

$611 \mathrm{NBO}$ and SOPT analyses on selected donor-acceptor interactions 612 in intermediate 2 were performed using the software NBO 6.0. ${ }^{73}$

\section{ASSOCIATED CONTENT}

\section{S1 Supporting Information}

615 The Supporting Information is available free of charge at 616 https://pubs.acs.org/doi/10.1021/acs.organomet.0c00459.
NMR and IR spectra of 2 and deuterated analogues, 617 comparison of $\mathbf{2}$ with other amidoborane complexes, 618 catalytic dehydrogenation of $\mathrm{AB}$ and other amine 619 boranes, gas evolution experiments, reaction of $\mathrm{Co}$ (III) 620 complexes with $\mathrm{KNH}_{2} \mathrm{BH}_{3}$, DFT data, crystallographic 621 parameters (PDF)

622

Accession Codes 623 CCDC 1999728 contain the supplementary crystallographic 624 data for complex 2. These data can be obtained free of charge 625 via www.ccdc.cam.ac.uk/data_request/cif, or by emailing 626 data_request@ccdc.cam.ac.uk, or by contacting The Cam-627 bridge Crystallographic Data Centre, 12 Union Road, 628 Cambridge CB2 1EZ, UK; fax: + 441223336033.

\section{AUTHOR INFORMATION}

Corresponding Authors

Max García-Melchor - School of Chemistry, CRANN and 632 AMBER Research Centres, Trinity College Dublin, College 633 Green, Dublin 2, Ireland; O orcid.org/0000-0003-1348- 634 4692; Email: fout@illinois.edu

Alison R. Fout - School of Chemical Sciences, University of 636 Illinois at Urbana-Champaign, Urbana, Illinois 61801, United 637 States; ○ orcid.org/0000-0002-4669-5835; 638 Email: garciamm@tcd.ie 639

Author 640

Joseph W. Nugent - School of Chemical Sciences, University of 641 Illinois at Urbana-Champaign, Urbana, Illinois 61801, United 642

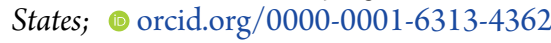

Complete contact information is available at:

https://pubs.acs.org/10.1021/acs.organomet.0c00459

643

Notes

644

645

The authors declare no competing financial interest.

646

All the DFT data underlying this work, including the Cartesian 648 coordinates of the modeled structures and energies, are 649 available at the following ioChem-BD online data set: 650 https://iochem-bd.bsc.es/browse/review-collection/100/ 651 194393/072224b9999729ba5ccea358.

652

\section{ACKNOWLEDGMENTS}

653

Financial support for this work was provided by the University 654 of Illinois at Urbana-Champaign (UIUC). J.W.N. is thankful 655 for a Robert C. \& Carolyn J. Springborn Fellowship and a 656 TechnipFMC fellowship. A.R.F. is an Alfred P. Sloan Research 657 Fellow and a Camille Dreyfus Teacher-Scholar. The authors 658 thank Prof. Gregory Girolami, Dr. Danielle Gray, and Dr. Toby 659 Woods for their help in solving the structure of 2. The DJEI/ 660 DES/SFI/HEA Irish Centre for High-End Computing 661 (ICHEC) is also acknowledged for the generous provision of 662 computational facilities and support.

663

\section{REFERENCES}

664

(1) Staubitz, A.; Robertson, A. P. M.; Sloan, M. E.; Manners, I. 665 Amine- and Phosphine-Borane Adducts: New Interest in Old 666 Molecules. Chem. Rev. 2010, 110, 4023-4078.

(2) Staubitz, A.; Robertson, A. P. M.; Manners, I. Ammonia-Borane 668 and Related Compounds as Dihydrogen Sources. Chem. Rev. 2010, 669 110, 4079-4124.

(3) Hamilton, C. W.; Baker, R. T.; Staubitz, A.; Manners, I. B-N 671 Compounds for Chemical Hydrogen Storage. Chem. Soc. Rev. 2009, 672 38, 279-293. 
674 (4) Sun, Q.; Wang, N.; Zhang, T.; Bai, R.; Mayoral, A.; Zhang, P.; 675 Zhang, Q.; Terasaki, O.; Yu, J. Zeolite-Encaged Single-Atom 676 Rhodium Catalysts: Highly-Efficient Hydrogen Generation and 677 Shape-Selective Tandem Hydrogenation of Nitroarenes. Angew. 678 Chem., Int. Ed. 2019, 58, 18570-18576.

679 (5) Rossin, A.; Peruzzini, M. Ammonia-Borane and Amine-Borane 680 Dehydrogenation Mediated by Complex Metal Hydrides. Chem. Rev. $6812016,116,8848-8872$.

682 (6) Bhunya, S.; Malakar, T.; Ganguly, G.; Paul, A. Combining 683 Protons and Hydrides by Homogeneous Catalysis for Controlling the 684 Release of Hydrogen from Ammonia-Borane: Present Status and 685 Challenges. ACS Catal. 2016, 6, 7907-7934.

686 (7) Keaton, R. J.; Blacquiere, J. M.; Baker, R. T. Base Metal 687 Catalyzed Dehydrogenation of Ammonia-Borane for Chemical 688 Hydrogen Storage. J. Am. Chem. Soc. 2007, 129, 1844-1845.

689 (8) Vogt, M.; de Bruin, B.; Berke, H.; Trincado, M.; Grützmacher, $690 \mathrm{H}$. Amino Olefin Nickel(I) and Nickel(0) Complexes as Dehydrogen691 ation Catalysts for Amine Boranes. Chem. Sci. 2011, 2, 723-727.

692 (9) Pun, D.; Lobkovsky, E.; Chirik, P. J. Amineborane Dehydrogen693 ation Promoted by Isolable Zirconium Sandwich, Titanium Sandwich 694 and N2 Complexes. Chem. Commun. 2007, No. 31, 3297-3299.

695 (10) Helten, H.; Dutta, B.; Vance, J. R.; Sloan, M. E.; Haddow, M. 696 F.; Sproules, S.; Collison, D.; Whittell, G. R.; Lloyd-Jones, G. C.; 697 Manners, I. Paramagnetic Titanium(III) and Zirconium(III) Metal698 locene Complexes as Precatalysts for the Dehydrocoupling/ 699 Dehydrogenation of Amine-Boranes. Angew. Chem., Int. Ed. 2013, 700 52, 437-440.

701 (11) Clark, T. J.; Russell, C. A.; Manners, I. Homogeneous, 702 Titanocene-Catalyzed Dehydrocoupling of Amine-Borane Adducts. J. 703 Am. Chem. Soc. 2006, 128, 9582-9583.

704 (12) Sloan, M. E.; Staubitz, A.; Clark, T. J.; Russell, C. A.; Lloyd705 Jones, G. C.; Manners, I. Homogeneous Catalytic Dehydrocoupling/ 706 Dehydrogenation of Amine-Borane Adducts by Early Transition 707 Metal, Group 4 Metallocene Complexes. J. Am. Chem. Soc. 2010, 132, 708 3831-3841.

709 (13) Lapierre, E. A.; Patrick, B. O.; Manners, I. Trivalent Titanocene 710 Alkyls and Hydrides as Well-Defined, Highly Active, and Broad Scope 711 Precatalysts for Dehydropolymerization of Amine-Boranes. J. Am. 712 Chem. Soc. 2019, 141, 20009-20015.

713 (14) Jurca, T.; Dellermann, T.; Stubbs, N. E.; Resendiz-Lara, D. A.; 714 Whittell, G. R.; Manners, I. Step-Growth Titanium-Catalysed 715 Dehydropolymerisation of Amine-Boranes. Chem. Sci. 2018, 9, $7163360-3366$.

717 (15) Muhammad, S.; Moncho, S.; Brothers, E. N.; Bengali, A. A. 718 Dehydrogenation of a Tertiary Amine-Borane by a Rhenium 719 Complex. Chem. Commun. 2014, 50, 5874-5877.

720 (16) Kawano, Y.; Uruichi, M.; Shimoi, M.; Taki, S.; Kawaguchi, T.; 721 Kakizawa, T.; Ogino, H. Dehydrocoupling Reactions of Borane722 Secondary and -Primary Amine Adducts Catalyzed by Group-6 723 Carbonyl Complexes: Formation of Aminoboranes and Borazines. J. 724 Am. Chem. Soc. 2009, 131, 14946-14957.

725 (17) Bera, B.; Jagirdar, B. R. Photolysis of Arene Chromium 726 Tricarbonyl Complexes in Presence of Amine-Boranes: Observation 727 of $\sigma$-Borane Complexes in Solution. Inorg. Chim. Acta 2011, 372, 728 200-205.

729 (18) Baker, R. T.; Gordon, J. C.; Hamilton, C. W.; Henson, N. J.; 730 Lin, P. H.; Maguire, S.; Murugesu, M.; Scott, B. L.; Smythe, N. C. 731 Iron Complex-Catalyzed Ammonia-Borane Dehydrogenation. A 732 Potential Route toward B-N-Containing Polymer Motifs Using 733 Earth-Abundant Metal Catalysts. J. Am. Chem. Soc. 2012, 134, $7345598-5609$.

735 (19) Vance, J. R.; Robertson, A. P. M.; Lee, K.; Manners, I. 736 Photoactivated, Iron-Catalyzed Dehydrocoupling of Amine-Borane 737 Adducts: Formation of Boron-Nitrogen Oligomers and Polymers. 738 Chem. - Eur. J. 2011, 17, 4099-4103.

739 (20) Vance, J. R.; Schäfer, A.; Robertson, A. P. M.; Lee, K.; Turner, 740 J.; Whittell, G. R.; Manners, I. Iron-Catalyzed Dehydrocoupling/ 741 Dehydrogenation of Amine-Boranes. J. Am. Chem. Soc. 2014, 136, $7423048-3064$.
(21) Bhattacharya, P.; Krause, J. A.; Guan, H. Mechanistic Studies of 743 Ammonia Borane Dehydrogenation Catalyzed by Iron Pincer 744 Complexes. J. Am. Chem. Soc. 2014, 136, 11153-11161. 745 (22) Glüer, A.; Förster, M.; Celinski, V. R.; Schmedt Auf Der 746 Günne, J.; Holthausen, M. C.; Schneider, S. Highly Active Iron 747 Catalyst for Ammonia Borane Dehydrocoupling at Room Temper- 748 ature. ACS Catal. 2015, 5, 7214-7217.

(23) Lunsford, A. M.; Blank, J. H.; Moncho, S.; Haas, S. C.; 750 Muhammad, S.; Brothers, E. N.; Darensbourg, M. Y.; Bengali, A. A. 751 Catalysis and Mechanism of H2Release from Amine-Boranes by 752 Diiron Complexes. Inorg. Chem. 2016, 55, 964-973. 753

(24) Knitsch, R.; Han, D.; Anke, F.; Ibing, L.; Jiao, H.; Hansen, M. 754 R.; Beweries, T. Fe(II) Hydride Complexes for the Homogeneous 755 Dehydrocoupling of Hydrazine Borane: Catalytic Mechanism via 756 DFT Calculations and Detailed Spectroscopic Characterization. 757 Organometallics 2019, 38, 2714-2723.

(25) Coles, N. T.; Mahon, M. F.; Webster, R. L. Phosphine- and 759 Amine-Borane Dehydrocoupling Using a Three-Coordinate Iron(II) 760 $\beta$-Diketiminate Precatalyst. Organometallics 2017, 36, 2262-2268. 761

(26) Lin, T. P.; Peters, J. C. Boryl-Mediated Reversible H2 762 Activation at Cobalt: Catalytic Hydrogenation, Dehydrogenation, 763 and Transfer Hydrogenation. J. Am. Chem. Soc. 2013, 135, 15310- 764 15313.

(27) Pagano, J. K.; Stelmach, J. P. W.; Waterman, R. Cobalt- 766 Catalyzed Ammonia Borane Dehydrocoupling and Transfer Hydro- 767 genation under Aerobic Conditions. Dalt. Trans. 2015, 44, 12074- 768 12077 .

(28) Todisco, S.; Luconi, L.; Giambastiani, G.; Rossin, A.; Peruzzini, 770 M.; Golub, I. E.; Filippov, O. A.; Belkova, N. V.; Shubina, E. S. 771 Ammonia Borane Dehydrogenation Catalyzed by $\left(\kappa^{4}-\mathrm{EP}_{3}\right) \mathrm{Co}(\mathrm{H}) 772$ $\left[\mathrm{EP}_{3}=\mathrm{E}\left(\mathrm{CH}_{2} \mathrm{CH}_{2} \mathrm{PPh}_{2}\right)_{3} ; \mathrm{E}=\mathrm{N}, \mathrm{P}\right]$ and $\mathrm{H} 2$ Evolution from Their 773 Interaction with NH Acids. Inorg. Chem. 2017, 56, 4296-4307. 774

(29) Maier, T. M.; Sandl, S.; Shenderovich, I. G.; Jacobi von 775 Wangelin, A.; Weigand, J. J.; Wolf, R. Amine-Borane Dehydrogen- 776 ation and Transfer Hydrogenation Catalyzed by $\alpha$-Diimine 777 Cobaltates. Chem. - Eur. J. 2019, 25, 238-245.

(30) Boyd, T. M.; Andrea, K. A.; Baston, K.; Johnson, A.; Ryan, D. 779 E.; Weller, A. S. A Simple Cobalt-Based Catalyst System for the 780 Controlled Dehydropolymerisation of H3B-NMeH2 on the Gram- 781 Scale. Chem. Commun. 2020, 56, 482-485.

(31) Ibrahim, A. D.; Entsminger, S. W.; Zhu, L.; Fout, A. R. A 783 Highly Chemoselective Cobalt Catalyst for the Hydrosilylation of 784 Alkenes Using Tertiary Silanes and Hydrosiloxanes. ACS Catal. 2016, 785 6, 3589-3593.

(32) Ibrahim, A. D.; Entsminger, S. W.; Fout, A. R. Insights into a 787 Chemoselective Cobalt Catalyst for the Hydroboration of Alkenes 788 and Nitriles. ACS Catal. 2017, 7, 3730-3734.

(33) Tokmic, K.; Markus, C. R.; Zhu, L.; Fout, A. R. Well-Defined 790 Cobalt(I) Dihydrogen Catalyst: Experimental Evidence for a Co(I)/ 791 Co(III) Redox Process in Olefin Hydrogenation. J. Am. Chem. Soc. 792 2016, 138, 11907-11913.

(34) Tokmic, K.; Fout, A. R. Alkyne Semihydrogenation with a 794 Well-Defined Nonclassical Co-H2 Catalyst: A H2 Spin on Isomer- 795 ization and E-Selectivity. J. Am. Chem. Soc. 2016, 138, 13700-13705. 796

(35) Tokmic, K.; Jackson, B. J.; Salazar, A.; Woods, T. J.; Fout, A. R. 797 Cobalt-Catalyzed and Lewis Acid-Assisted Nitrile Hydrogenation to 798 Primary Amines: A Combined Effort. J. Am. Chem. Soc. 2017, 139, 799 13554-13561.

(36) Matus, M. H.; Grant, D. J.; Nguyen, M. T.; Dixon, D. A. 801 Fundamental Thermochemical Properties of Ammonia Borane and 802 Dehydrogenated Derivatives (BNHn, $\mathrm{n}=0-6)$. J. Phys. Chem. C 803 2009, 113, 16553-16560.

(37) Kirwan, J. N.; Roberts, B. P. Homolytic Reactions of Ligated 805 Boranes. Part 11. 'Electron Spin Resonance Studies of Radicals 806 Derived from Primary Amine-Boranes. J. Chem. Soc., Perkin Trans. 2807 1989, 539-550. 808

(38) Rablen, P. R. Large Effect on Borane Bond Dissociation 809 Energies Resulting from Coordination by Lewis Bases. J. Am. Chem. 810 Soc. 1997, 119, 8350-8360. 
812 (39) Arduengo, A. J.; Dixon, D. A. Project Title: Main Group Element 813 Chemistry in Service of Hydrogen Storage and Activation; DOE Award 814 Number DE-FC36-05GO15059; Department of Energy, 2010; p 53. 815 (40) Forster, T. D.; Tuononen, H. M.; Parvez, M.; Roesler, R. 816 Characterization of $\beta$-B-Agostic Isomers in Zirconocene Amidobor817 ane Complexes. J. Am. Chem. Soc. 2009, 131, 6689-6691.

818 (41) Wolstenholme, D. J.; Traboulsee, K. T.; Decken, A.; McGrady, 819 G. S. Structure and Bonding of Titanocene Amidoborane Complexes: 820 A Common Bonding Motif with Their B-Agostic Organometallic 821 Counterparts. Organometallics 2010, 29, 5769-5772.

822 (42) Shannon, R. D. Revised Effective Ionic Radii and Systematic 823 Studies of Interatomic Distances in Halides and Chalcogenides. Acta 824 Crystallogr., Sect. A: Cryst. Phys., Diffr., Theor. Gen. Crystallogr. 1976, 825 32, 751-767.

826 (43) Spielmann, J.; Jansen, G.; Bandmann, H.; Harder, S. Calcium 827 Amidoborane Hydrogen Storage Materials: Crystal Structures of 828 Decomposition Products. Angew. Chem., Int. Ed. 2008, 47, 62908296295

830 (44) Spielmann, J.; Piesik, D. E. J.; Harder, S. Thermal 831 Decomposition of Mono- and Bimetallic Magnesium Amidoborane 832 Complexes. Chem. - Eur. J. 2010, 16, 8307-8318.

833 (45) Bellham, P.; Hill, M. S.; Kociok-Köhn, G.; Liptrot, D. J. 834 Alkaline Earth Alkyl Insertion Chemistry of in Situ Generated 835 Aminoboranes. Dalt. Trans. 2013, 42, 737-745.

836 (46) Bellham, P.; Hill, M. S.; Kociok-Köhn, G. Stoichiometric and 837 Catalytic Reactivity of Tert-Butylamine-Borane with Calcium 838 Silylamides. Organometallics 2014, 33, 5716-5721.

839 (47) Bellham, P.; Anker, M. D.; Hill, M. S.; Kociok-Köhn, G.; 840 Mahon, M. F. The Significance of Secondary Interactions during 841 Alkaline Earth-Promoted Dehydrogenation of Dialkylamine-Boranes. 842 Dalt. Trans. 2016, 45, 13969-13978.

843 (48) Schnieders, D.; Tsui, B. T. H.; Sung, M. M. H.; Bortolus, M. R.; 844 Schrobilgen, G. J.; Neugebauer, J.; Morris, R. H. Metal Hydride 845 Vibrations: The Trans Effect of the Hydride. Inorg. Chem. 2019, 58, 846 12467-12479.

847 (49) Spearing-Ewyn, E. A. K.; Beattie, N. A.; Colebatch, A. L.; 848 Martinez-Martinez, A. J.; Docker, A.; Boyd, T. M.; Baillie, G.; Reed, 849 R.; Macgregor, S. A.; Weller, A. S. The Role of Neutral Rh(PONOP)$850 \mathrm{H}$, Free $\mathrm{NMe} 2 \mathrm{H}$, Boronium and Ammonium Salts in the 851 Dehydrocoupling of Dimethylamine-Borane Using the Cationic 852 Pincer $[\mathrm{Rh}(\mathrm{PONOP})(\mathrm{H} 2-\mathrm{H} 2)]+$ Catalyst. Dalt. Trans. 2019, 48, 853 14724-14736.

854 (50) Bhunya, S.; Zimmerman, P. M.; Paul, A. Unraveling the Crucial 855 Role of Metal-Free Catalysis in Borazine and Polyborazylene 856 Formation in Transition-Metal-Catalyzed Ammonia-Borane Dehy857 drogenation. ACS Catal. 2015, 5, 3478-3493.

858 (51) Shaw, W. J.; Linehan, J. C.; Szymczak, N. K.; Heldebrant, D. J.; 859 Yonker, C.; Camaioni, D. M.; Baker, R. T.; Autrey, T. In Situ 860 Multinuclear NMR Spectroscopic Studies of the Thermal Decom861 position of Ammonia Borane in Solution. Angew. Chem., Int. Ed. 2008, 862 47, 7493-7496.

863 (52) Kalviri, H. A.; Gärtner, F.; Ye, G.; Korobkov, I.; Baker, R. T. 864 Probing the Second Dehydrogenation Step in Ammonia-Borane 865 Dehydrocoupling: Characterization and Reactivity of the Key 866 Intermediate, B-(Cyclotriborazanyl)Amine-Borane. Chem. Sci. 2015, $8676,618-624$

868 (53) Davis, B. L.; Rekken, B. D.; Michalczyk, R.; Garner, E. B., III; 869 Dixon, D. A.; Kalviri, H.; Baker, R. T.; Thorn, D. L. Lewis Base 870 Assisted B-H Bond Redistribution in Borazine and Polyborazylene. 871 Chem. Commun. 2013, 49, 9095-9097.

872 (54) Briggs, T. S.; Gwinn, W. D.; Jolly, W. L.; Thorne, L. R. 873 Synthesis, Characterization, and Structure of Diaminoborane. J. Am. 874 Chem. Soc. 1978, 100, 7762-7763.

875 (55) Yang, X.; Zhao, L.; Fox, T.; Wang, Z. X.; Berke, H. Transfer 876 Hydrogenation of Imines with Ammonia-Borane: A Concerted 877 Double-Hydrogen-Transfer Reaction. Angew. Chem., Int. Ed. 2010, 878 49, 2058-2062.

879 (56) Büschelberger, P.; Reyes-Rodriguez, E.; Schöttle, C.; Treptow, 880 J.; Feldmann, C.; Jacobi Von Wangelin, A.; Wolf, R. Recyclable
Cobalt(0) Nanoparticle Catalysts for Hydrogenations. Catal. Sci. 881 Technol. 2018, 8, 2648-2653.

(57) Pons, V.; Baker, R. T.; Szymczak, N. K.; Heldebrant, D. J.; 883 Linehan, J. C.; Matus, M. H.; Grant, D. J.; Dixon, D. A. Coordination 884 of Aminoborane, $\mathrm{NH}_{2} \mathrm{BH}_{2}$, Dictates Selectivity and Extent of $\mathrm{H}_{2} 885$ Release in Metal-Catalysed Ammonia Borane Dehydrogenation. 886 Chem. Commun. 2008, No. 48, 6597-6599.

(58) Marziale, A. N.; Friedrich, A.; Klopsch, I.; Drees, M.; Celinski, 888 V. R.; Schmedt Auf Der Günne, J.; Schneider, S. The Mechanism of 889 Borane-Amine Dehydrocoupling with Bifunctional Ruthenium 890 Catalysts. J. Am. Chem. Soc. 2013, 135, 13342-13355. 891

(59) Esteruelas, M. A.; López, A. M.; Mora, M.; Oñate, E. Ammonia- 892 Borane Dehydrogenation Promoted by an Osmium Dihydride 893 Complex: Kinetics and Mechanism. ACS Catal. 2015, 5, 187-191. 894

(60) Kumar, A.; Johnson, H. C.; Hooper, T. N.; Weller, A. S.; 895 Algarra, A. G.; Macgregor, S. A. Multiple Metal-Bound Oligomers 896 from Ir-Catalysed Dehydropolymerisation of H3B-NH3as Probed by 897 Experiment and Computation. Chem. Sci. 2014, 5, 2546-2553. 898

(61) Pangborn, A. B.; Giardello, M. A.; Grubbs, R. H.; Rosen, R. K.; 899 Timmers, F. J. Safe and Convenient Procedure for Solvent 900 Purification. Organometallics 1996, 15, 1518-1520.

(62) Blaquiere, N.; Diallo-Garcia, S.; Gorelsky, S. I.; Black, D. A.; 902 Fagnou, K. Ruthenium-Catalyzed Dehydrogenation of Ammonia 903 Boranes. J. Am. Chem. Soc. 2008, 130, 14034-14035.

(63) David, W. I. F.; Shrestha, R. P.; Jones, M. O.; Edwards, P. P.; 905 Nakagawa, T.; Scott, B. L.; Ryan, K. R.; Burrell, A. K.; Diyabalanage, 906 H. V. K.; Semelsberger, T. A.; Davis, B. L. Potassium(I) 907 Amidotrihydroborate: Structure and Hydrogen Release. J. Am. 908 Chem. Soc. 2010, 132, 11836-11837.

(64) APEX2; Bruker AXS, Inc.: Madison, WI, 2004.

909

(65) Krause, L.; Herbst-Irmer, R.; Sheldrick, G. M.; Stalke, D. 91 Comparison of Silver and Molybdenum Microfocus X-Ray Sources 912 for Single-Crystal Structure Determination. J. Appl. Crystallogr. 2015, 913 $48,3-10$.

(66) Sheldrick, G. M. SHELXT - Integrated space-group and 915 crystal-structure determination. Acta Crystallogr., Sect. A: Found. Adv. 916 2015, 71, 3-8.

(67) Sheldrick, G. M. Crystal structure refinement with SHELXL. 918 Acta Crystallogr., Sect. C: Struct. Chem. 2015, 71, 3-8.

(68) Dolomanov, O. V.; Bourhis, L. J.; Gildea, R. J.; Howard, J. A. 920 K.; Puschmann, H. OLEX2: A Complete Structure Solution, 921 Refinement and Analysis Program. J. Appl. Crystallogr. 2009, 42, 922 339-341.

923

(69) Chai, J.-D.; Head-Gordon, M. Long-Range Corrected Hybrid 924 Density Functionals with Damped Atom-Atom Dispersion Correc- 925 tions. Phys. Chem. Chem. Phys. 2008, 10, 6615-6620.

926

(70) Frisch, M. J.; Trucks, G. W.; Schlegel, H. B.; Scuseria, G. E.; 927 Robb, M. A.; Cheeseman, J. R.; Scalmani, G.; Barone, V.; Mennucci, 928 B.; Petersson, G. A.; Nakatsuji, H.; Caricato, M.; Li, X.; Hratchian, H. 929 P.; Izmaylov, A. F.; Bloino, J.; Zheng, G.; Sonnenberg, J. L.; Hada, M.; 930 Ehara, M.; Toyota, K.; Fukuda, R.; Hasegawa, J.; Ishida, M.; 931 Nakajima, T.; Honda, Y.; Kitao, O.; Nakai, H.; Vreven, T.; 932 Montgomery, J. A., Jr.; Peralta, J. E.; Ogliaro, F.; Bearpark, M.; 933 Heyd, J. J.; Brothers, E.; Kudin, K. N.; Staroverov, V. N.; Kobayashi, 934 R.; Normand, J.; Raghavachari, K.; Rendell, A.; Burant, J. C.; Iyengar, 935 S. S.; Tomasi, J.; Cossi, M.; Rega, N.; Millam, J. M.; Klene, M.; Knox, 936 J. E.; Cross, J. B.; Bakken, V.; Adamo, C.; Jaramillo, J.; Gomperts, R.; 937 Stratmann, R. E.; Yazyev, O.; Austin, A. J.; Cammi, R.; Pomelli, C.; 938 Ochterski, J. W.; Martin, R. L.; Morokuma, K.; Zakrzewski, V. G.; 939 Voth, G. A.; Salvador, P.; Dannenberg, J. J.; Dapprich, S.; Daniels, A. 940 D.; Farkas, O.; Foresman, J. B.; Ortiz, J. V.; Cioslowski, J.; Fox, D. J. 941 Gaussian 09, revision A.02; Gaussian, Inc.: Wallingford, CT, 2009.942 (71) Ehlers, A. W.; Böhme, M.; Dapprich, S.; Gobbi, A.; Höllwarth, 943 A.; Jonas, V.; Köhler, K. F.; Stegmann, R.; Veldkamp, A.; Frenking, G. 944 A Set of F-Polarization Functions for Pseudo-Potential Basis Sets of 945 the Transition Metals Sc-Cu, Y-Ag and La-Au. Chem. Phys. Lett. 1993, 946 208, 111-114.

(72) Marenich, A. V.; Cramer, C. J.; Truhlar, D. G. Universal 948 Solvation Model Based on Solute Electron Density and on a 949 
950 Continuum Model of the Solvent Defined by the Bulk Dielectric 951 Constant and Atomic Surface Tensions. J. Phys. Chem. B 2009, 113, $9526378-6396$.

953 (73) Glendening, E. D.; Badenhoop, J. K.; Reed, A. E.; Carpenter, J. 954 E.; Bohmann, J. A.; Morales, C. M.; Landis, C. R.; Weinhold, F. NBO 955 6.0; Theoretical Chemistry Institute, University of Wisconsin: 956 Madison, WI, 2013. http://nbo6.chem.wisc.edu/. 